\begin{tabular}{l|ll} 
upf. & $\begin{array}{l}\text { Universitat } \\
\text { Pompeu Fabra } \\
\text { Barcelona }\end{array}$ & $\begin{array}{l}\text { Department } \\
\text { of Economics and Business }\end{array}$ \\
\hline
\end{tabular}

Economics Working Paper Series

Working Paper No. 1693

\title{
Winners and losers from sovereign debt inflows: evidence from the stock market
}

Fernando Broner, Alberto Martin, Lorenzo Pandolfi, and Tomas Williams

December 2019 


\title{
Winners and Losers from Sovereign Debt Inflows: Evidence from
}

\section{the Stock Market*}

\author{
Fernando Broner ${ }^{1}$, Alberto Martin ${ }^{2}$, Lorenzo Pandolfi ${ }^{3}$, and Tomas Williams ${ }^{4}$ \\ ${ }^{1} \mathrm{CREi}$ and Barcelona GSE \\ ${ }^{2}$ European Central Bank, CREi, Barcelona GSE \\ ${ }^{3}$ University of Naples Federico II and CSEF \\ ${ }^{4}$ George Washington University
}

December 2019

\begin{abstract}
This paper analyzes the effects on firms of sovereign debt inflows in emerging countries. To deal with the endogeneity between capital inflows and economic activity, we focus on capital inflows driven by countries' inclusions into well-known local currency sovereign debt market indexes. These events convey little information about the future economic prospects of countries but induce large capital flows from institutional investors tracking the indexes. We show that inclusion-driven flows significantly reduce government bond yields and appreciate the domestic currency. In turn, these flows have heterogenous impact on firms' stock market returns. Government related firms, financial firms and firms with larger financial constraints experience positive abnormal returns following the announcement of these events. Instead, companies operating in export-intensive sectors have negative abnormal returns. Our findings shed novel light on the channels through which capital inflows to sovereign debt markets affect firms in the economy.
\end{abstract}

JEL Classification: F31, F32, F36, G15, G23

Keywords: Sovereign debt; capital inflows; exchange rate; government bond yields; external financial dependence

\footnotetext{
${ }^{*}$ We gratefully acknowledge financial support from the Einaudi Institute for Economics and Finance (2017 EIEF research grant) and the Columbian College Facilitating Fund from George Washington University. We are grateful to Graciela Kaminsky, Tommaso Oliviero, Marco Pagano, and Tom Schmitz, participants at the DebtCon3 conference for insightful comments and suggestions, to Colton Larson for excellent research assistance, and to Mariano Cosentino for helping us with the data for this paper. All errors remain ours.
} 


\section{Introduction}

The rise of financial globalization made cross-border capital flows grow exponentially in the last three decades. As a consequence, foreign participation in local markets increased, increasing the exposure of countries' to shocks from these foreign investors. Sovereign debt markets are no exception. The loosening of capital controls and investors' search for yield in emerging markets contributed to the surge in popularity of international fixed income benchmark indexes, and led to an increase in the foreign investor base of emerging countries' sovereign debt from $18 \%$ to $30 \%$ in the last ten years, as Figure 1 highlights.

Despite the importance of this phenomenon, there is little evidence on the implications for domestic firms of demand-driven capital inflows to sovereign debt markets. From a theoretical point of view, in a frictionless small open economy model, these inflows should not affect domestic firms. In such world, government bond yields should only be affected by changes in global interest rate and countries' probability of default. In addition, the exchange rate should follow interest rate

parity. Thus, capital movements owing to shocks in the foreign demand for domestic sovereign debt play no roles in these models, and in the end, do not affect firms.

However, there is substantial evidence showing that asset markets are, in fact, segmented, implying that supply and demand forces can influence asset prices and push them away from fundamentals. Consequently, capital inflows to sovereign debt markets could reduce government bond yields and appreciate the domestic currency. If that is the case, these inflows could have important consequences for firms in the economy as well. For instance, financial institutions that hold government debt can experience a positive balance sheet shock and react by expanding their supply of credit to financially constrained firms in the economy (Gennaioli et al. (2014)). Also, firms operating in tradable sectors can see their competitiveness and profitability eroded by the appreciation of the local currency (Gabaix and Maggiori (2015)).

These contrasting predictions, together with the recent upsurge of international capital flows, call for a deeper understanding of the implications of sovereign debt inflows for domestic firms. Do 
local economies benefit from large inflows? And, more importantly, what are the channels through which foreign demand shocks are transmitted to the real economy? Addressing these questions is as crucial as challenging from an empirical point of view mostly because of an important identification challenge. Changes in foreign demand for sovereign bonds that cause capital inflows are jointly determined with sovereign risk, exchange rates and the economic activity. For instance, a positive technological or political shock improving the domestic economic activity of a country may reduce sovereign risk and at the same time attract foreign investors. The resulting positive correlation between capital inflows and economic activity would clearly not imply any causal relationship.

In this paper, we overcome this identification challenge by exploiting six episodes of large capital inflows driven by foreign demand shocks that are unrelated to changes in a country's economic prospects. Specifically, we take advantage of sudden and unanticipated announcements made by two major index providers of a country's inclusion in their international indexes of local currencydenominated sovereign debt. We use these episodes to study how the capital flows triggered by the announcements affect the stock market returns of domestic companies. The countries affected by these inclusions are Colombia, Czech Republic, Mexico, Nigeria, Romania, and South Africa. The indexes we focus on are the Citigroup World Government Bond Index (WGBI) and the J.P. Morgan Government Bond Index Emerging Markets (GBI-EM), two of the most widely tracked benchmarks for international investors in fixed income markets. Precisely because many large institutional investors track their performance against these indexes, the inclusion announcements induce large rebalancings in their portfolios boosting the demand for both government bonds and local currency.

These inclusion events provide an ideal setting to address our research question. First, the inflows triggered by the inclusion announcements are unexpected, and are due to international investors' willingness to replicate the composition of their benchmark indexes. In fact, we show that i) announcement dates are not previously anticipated by index providers; ii) around these dates, no important news about the economy of affected countries nor about changes in government policies is released. Second, the two indexes we consider are exclusively composed of sovereign bonds, so that their rebalancings only entail inflows to the sovereign bond markets and not to the equity 
nor to the corporate debt markets. ${ }^{1}$ These features of these episodes allows us to adopt an event study methodology around the announcement dates to analyze whether the flows driven by the announced rebalancing of the index affect the cost of government debt and the exchange rate and, consequently, the stock market returns of domestic firms.

We show that foreign demand shocks for domestic sovereign bonds strongly affect government bond yields and exchange rates. Consistent with the view of segmented asset markets, government bond yields drop in the aftermath of the announcement dates for all the countries in our sample. Similarly, the increased foreign demand for local currency leads to a significant exchange rate appreciation.

Given their implications for these two key macroeconomic prices, capital inflows to the sovereign debt market also have sizable and heterogeneous effects on the market value of domestic firms. While the average stock market returns of listed firms is close to zero around the rebalancing dates, this result masks important heterogeneous effects going in opposite directions. On the one hand, financial firms - which are more likely to hold government bonds in their portfolios - and government related firms benefit from the reduction in government bond yields. On the other hand, firms operating in tradable sectors, which are more likely to export their production abroad, suffer from the negative profitability shock owing to the appreciated exchange rate. Figure 2 provides a visual representation of these results. Beyond these direct effects, the government bond yield channel also has an indirect effect on financially constrained firms in the economy. As financial firms, mostly banks, experience a positive balance sheet shock, they can extend more credit to firms, thus alleviating the constraints of firms that rely more heavily on external sources of financing. Consistent with this, firms with greater external financial dependence experience larger than average stock market returns at the rebalancing date.

Quantitatively, we find that capital inflows to sovereign debt markets that lead to a 100 basis points reduction in the 5-year government bond yield lead to 1.7 percentage points higher cumulative abnormal returns for financial and government related firms relative to the rest of firms in the

\footnotetext{
${ }^{1}$ Additional features of the inclusion events are given in Section 2.2, while we devote Section 4.1 to discuss in greater detail our identification assumptions.
} 
economy. In turn, capital inflows that lead to a $1 \%$ appreciation of the exchange rate, make cumulative returns from firms in tradable, export-intensive sectors 0.5 percentage points lower than those of the other domestic companies in the country. Finally, firms in the upper quartile of the distribution of external financial dependance (computed following Rajan and Zingales (1998)), experience 0.7 percentage points higher cumulative abnormal returns than firms in the lowest quartile of the same distribution when the country is hit by a capital inflow shock that lowers the government bond yield by 100 basis point.

Along our results, we perform several robustness and placebo exercises that lend important support to our empirical strategy. First, we show that all of these effects are economically and statistically close to zero in the days prior to the rebalancing dates. In addition, we show that the cumulative returns around the rebalancing dates are not linked to other firm characteristics that are unrelated with the yield or the exchange rate channels, as for instance the reliance on corporate debt, firm size, or the share of foreign shareholders.

Our paper contributes to several strands of the literature. First, we contribute to a growing literature on the channels through which capital flows affect firms in the economy. ${ }^{2}$ Much of this literature has focused on FDI, bank flows or equity portfolio flows. In this paper, we show that even capital inflows to the sovereign debt market can affect firms through different channels.

Additionally, our results are closely related to studies of demand shocks in financial markets, and especially to those focusing on the government debt market. ${ }^{3}$ We contribute to this literature by showing how these shocks can spillover to firms' stock market value through different mechanisms.

Finally, there has been a broad literature that analyzes the relationship between sovereign debt markets, sovereign defaults, financial institutions and the consequences for economic activity. ${ }^{4}$ The

\footnotetext{
${ }^{2}$ See among others Schnabl (2012), Alfaro et al. (2014), Lane and McQuade (2014), Benigno et al. (2015), Blanchard et al. (2017), Gabaix and Maggiori (2015), Baskaya et al. (2017), and Calomiris et al. (2018). There is also a large literature on capital account liberalizations and their effects on firm stock market value (Chari and Henry (2004), Chari and Blair Henry (2008) and Larrain (2015) among others.

${ }^{3}$ See for example Warnock and Warnock (2009), Vayanos and Vila (2009), Greenwood and Vayanos (2010), Krishnamurthy and Vissing-Jorgensen (2011), Kohn (2017), Krishnamurthy et al. (2017), and Pandolfi and Williams (2019)

${ }^{4}$ Hébert and Schreger (2017), Andrade and Chhaochharia (2018), and Chari et al. (2018) analyze the costs of sovereign default using stock market data. There is also a large literature on the relationship between government debt, financial institutions, and bank lending. See among others Bolton and Jeanne (2011), Becker and Ivashina (2018),
} 
evidence presented in this paper shows that even exogenous foreign demand shocks to sovereign debt can spillover to firms' stock market value.

This paper is structured as follows. Section 2 presents the institutional setting and details our empirical strategy with the use of country inclusions as capital inflows shocks. Section 3 presents the event study methodology and results for how sovereign inflow shocks affect firms. Section 4 discusses the identification threars and robustness tests. Section 5 concludes.

\section{Empirical Strategy}

\subsection{Theoretical Background and Testable Implications}

In a frictionless small open economy model, shocks in foreigners' demand for local currency sovereign debt which are uncorrelated with changes in the fundamentals of the recipient country should have no impact on the domestic economy. In imperfect financial markets, however, sovereign debt inflows due to an increased foreign demand for sovereign bonds can be transmitted to the domestic economy through different channels. In this section, we develop a framework where we highlight two main channels through which capital inflow shocks can be transmitted to the domestic economy: the exchange rate and the sovereign bond yields.

When foreign investors increase their demand for the local currency denominated sovereign bonds in a given country, the price of these bonds rise, thus lowering sovereign bonds yields. This sudden and unexpected increase in sovereign bond prices and the associated drop in the sovereign bond yields could potentially affect firms in the recipient country. Moreover, the effect could be heterogeneous depending on each firm's sensitivity to changes in sovereign bond yields. For instance, financial institutions which own local currency denominated domestic government debt in their portfolios could experience a positive balance sheet shock when the inflows occur as suggested by Gennaioli et al. (2014). Aditionally, there could be a reduction in the crowding

Broner et al. (2014), Gennaioli et al. (2014), Gennaioli et al. (2018), Altavilla et al. (2017), Perez (2015), Baskaya and Kalemli-Ozcan (2016), Ongena et al. (2019) and Williams (2018). 
out of government debt or in the financial repression and moral suasion of the government on banks (Becker and Ivashina (2018), Ongena et al. (2019) and Williams (2018)). These effects could improve the financial conditions of domestic financial institutions. On top of this, these shocks could translate into an increased supply of credit by affected financial institutions. Therefore, financially constrained firms can optimally increase their leverage, thus increasing their profitability. Also, given the associated reduction in the government borrowing costs, this could positively affect the profitability of firms which are more connected to the domestic government - either because of their ownership structure, or because they rely more on government demand for their products (Chari et al. (2018)).

At the same time, sovereign debt inflow shocks - as well as other type of capital inflow shocks - appreciate the domestic currency. International investors who buy sovereign bonds denominated in local currency increase their demand for the domestic currency as well. In the presence of arbitrageurs with limited risk-bearing capacity (as in Gabaix and Maggiori (2015)), this increased demand for the local currency leads to an appreciation of the exchange rate. Because of the appreciation of the local currency, sovereign debt inflows shocks could erode the competitive advantage of firms operating in exporting and tradable industries (also shown in Gabaix and Maggiori (2015)).

Hence, the results from the framework show two forces at work when massive sovereign debt inflows enter a country: one is the expansionary effect of the reduction in sovereign bond yields, and the other one is the contractionary effect of the appreciation of the local currency. As a result, sovereign debt inflows due to foreigners' demand shocks can be both contractionary and expansionary for the recipient country, depending on the sensitivity of domestic firms to either of the two channels, and the composition of the domestic economy. Countries which are poorly financially developed and whose economies rely significantly on exports can see their competitiveness eroded by the entrance of foreign investors into the domestic sovereign debt market. Conversely, countries with a sufficiently large financial sector and limited dependency on exports can benefit from these shocks because of the positive balance sheet shocks experienced by financial institutions and the associated credit supply increase, as well as through the government's lower borrowing costs. 


\subsection{Country Inclusions as Capital Inflow Shocks}

In order to analyze the consequences of sovereign debt inflows for domestic firms, we exploit episodes of country inclusion in two major global local currency sovereign debt indexes which are widely used as benchmarks by international investors: the Citigroup WGBI and the JP Morgan GBI-EM. ${ }^{5}$ Specifically, the episodes we exploit are the inclusions in the GBI-EM of local currency denominated sovereign bonds issued by the governments of Colombia, Czech Republic, Nigeria, and Romania. These were announced on the $19^{\text {th }}$ of March 2014, the $23^{\text {rd }}$ of February 2017, the $17^{\text {th }}$ of August 2012 , and the $16^{\text {th }}$ of January 2013, respectively. We also analyze the inclusions in the WGBI of Mexican and Southern African local currency denominated sovereign bonds. These were announced on the $31^{\text {st }}$ of March 2010 and the $17^{\text {th }}$ of April 2012, respectively. Our sample period therefore spans from 2010 to $2018 .^{6}$

These inclusion events constitute an ideal laboratory to address our research question as they trigger massive sovereign debt inflows by foreign investors. International investors who are benchmarked against each index have indeed the incentive to rebalance their portfolios, purchasing sovereign bonds of the newly included country, just to replicate the index composition. ${ }^{7}$ Even though the inclusion is usually implemented gradually by index providers over the 3 to 12 months subsequent to the announcement, more active investors have the incentive to start rebalancing their portfolios already at the announcement date in order to minimize the cost of the rebalancing. ${ }^{8}$ This is something that can be observed in Figure 3, where we plot the foreign share of government debt for the around the announcement date. Even in the first quarter after the announcement quarter, there is a sizable increase in the presence of foreing investors in the sovereign debt market. Thus, on the announcement date, each country experiences a sudden and unexpected shock in the foreign demand for its local currency-denominated sovereign debt.

\footnotetext{
${ }^{5}$ For more details on how these indexes are created and their importance see Section B in the Appendix.

${ }^{6}$ Malaysia and Poland were also included in the WGBI during our sample period but we exclude them from our analysis since we could not identify a clear and univoque announcement date, which is crucial for our identification strategy.

${ }^{7}$ Evidence of international investors' tendency to replicate the composition of the indexes they track is abundant in the literature. See for instance Cremers et al. (2016) and Raddatz et al. (2017).

${ }^{8}$ Conversely, purely passive investors or exchange-traded funds who do not want to deviate from the index composition at any point in time will wait until the actual rebalancing of the index occurs.
} 
To get an idea of the magnitude of these inclusion-driven shocks, we follow Pandolfi and Williams (2019) and adapt their Flows Implied by Rebalancings (FIR) measure to our setting. ${ }^{9}$ Thus, we compute the estimated inflow shocks to the sovereign debt market of each country as the change in benchmark weight - calculated over the entire implementation period - multiplied by the assets under management of funds tracking their returns against the corresponding benchmark index, normalized by the size (total market value) of each country's sovereign debt market prior to the announcement. The FIR measure captures the potential inflows that would enter the country if all institutional investors were to precisely replicate the index composition. For the episodes in our sample the estimated FIR is $18 \%$ in Colombia, $25 \%$ in Czech Republic, $12 \%$ in Mexico, $31 \%$ in Nigeria, $30 \%$ in Romania, and $10 \%$ in South Africa. It is evident that the rebalancing-driven inflows following the inclusion in each index are very large, especially if compared to the overall market capitalization of their sovereign debt markets.

Besides being sizable, these events share some key features on which we base our identification. First, the date in which the index provider announces the inclusion is unexpected. Of course, the inclusion in itself does not come as a complete surprise, as markets in most cases were expecting these countries to get included into the index at some point in the future. In fact, some some of the countries in our sample had been already included in a watchlist before the announcement date. However, the exact timing of the inclusion in the index is not anticipated by investors. Indeed, not all countries that are included in a watchlist make it to the index, and when this happens, the time spanning between the inclusion in the watchlist and the inclusion in the index can be widely heterogeneous. This prevents international investors to forecast the effective inclusion period by simply looking at the dates countries get included into the watchlist. ${ }^{10}$

Second, the announcements made by index providers are not contemporaneous to macroe-

\footnotetext{
${ }^{9}$ Differently from Pandolfi and Williams (2019), who exploit small monthly rebalancings for which the announcement and implementation dates coincide, we exploit large rebalancings that are implemented over a longer time horizon. To calculate the aggregate inflows resulting from each rebalancing, we compute the change in benchmark weights as the cumulative change from the day before the announcement to that following the end of the implementation.

${ }^{10}$ Consistent with the unexpected nature of the shock, in Subsection 2.4, we show that 5-year government bond yields in the affected countries always drop significantly at the exact date in which the inclusion is announced, which makes implausible that markets were anticipating the event and trading accordingly in the days prior to the announcement dates.
} 
conomic shocks nor to relevant policy changes which might have a direct effect on stock prices. ${ }^{11}$ Also, the announcements do not convey country-specific information about some unobserved factors which might be affecting stock prices through channels other than sovereign debt inflows shocks. If that was true and the events were disclosing positive information about the fundamentals of countries to international investors, they should be followed by massive inflows not only to the sovereign debt market but also to the private debt market. Similarly, if the events were disclosing positive information about the quality of affected countries' sovereign debt - for instance, a decreased probability of default - the price of foreign currency denominated bonds should increase as well after the announcements. In Subsection 4.1 we show that most of the capital inflows in the aftermath of the announcements are concentrated in sovereign debt markets, and that yields on foreign currency denominated bonds do not decrease sharply as the ones on local currency denominated bonds on the announcement date. Hence, each inclusion event triggers a large sovereign debt inflow shock which is not only unexpected but also reasonably exogeneous to the stock market returns of domestic listed firms in the days around the announcement. Thus, by using these events as an instrument for sovereign debt inflows we can overcome the typical endogeneity of capital inflows and economic activity. This allows us to investigate the impact the former have on the latter and the different transmission channels to firms.

\subsection{Data}

To conduct the empirical analysis, we combine data from several sources. We collect from Datastream the time-series of daily (end-of-day) stock prices of domestic public companies for each of the six countries experiencing a major capital inflow shock as explained in the previous section. These countries are: Colombia, Czech Republic, Mexico, Nigeria, Romania, and South Africa. We gather additional information companies in these countries, including the International Securities Identification Number (ISIN), their industry classification, and a concise description of their business from

\footnotetext{
${ }^{11}$ Precisely because of this, the inclusion of Argentina in the GBI-EM and the exclusion of Nigeria from the GBI-EM are not part of our sample. In both cases the inclusion/exclusion event coincides with changes in capital controls adopted by these countries. Those events can hardly be thought as capital inflows shocks only to the sovereign debt market, since they might have effects on other markets.
} 
Datastream. Additionally, we use end-of-year balance sheet data from Worldscope.

We use financial market information to measure the shock in terms of government bond yields and the exchange rate. Local currency 5-year government bond yields are from Bloomberg. The time-series of daily (end-of-day) exchange rates are from Datastream. The exchange rate is computed as the amount of local currency needed to buy one US dollar. To compute abnormal returns, we use different global and local factors. From Datastream we obtain the time-series of daily returns on the Standard \& Poor's (S\&P) 500 index, the MSCI World Index, the MSCI Emerging Markets Index and the stock market indexes of each of the six countries in the sample. ${ }^{12}$ Risk-free interest rates come from the Federal Reserve Economic Research (FRED) database, and corresponds to the US 10-year Treasury yield.

To exploit across-companies heterogeneity in their exposure to capital inflows shocks, we supplement these data with additional firm-specific information. We are especially interested in identifying firms with relationship to the government. For that, we proceed in two steps. First, from Thomson Reuters Securities Data Company (SDC) Platinum we obtain the list of state owned firms, which we use to identify government owned firms in our sample. ${ }^{13}$ Second, we perform a search in the business description of firms and look for the words government or public. We use this information to generate the indicator variable $\mathbb{1}_{\text {Public }}$, which equals one if a company is (partially or totally) owned by the domestic government or in its business description it has the words government or public. Furthermore, we identify financial firms from the industry classification from Datastream (banks, financial firms, investment firms, and life insurance companies), and construct an indicator variable to identify them $\mathbb{1}_{\text {Financial }}$. The combination of both indicator variables is one of our main variables of interest, $\mathbb{1}_{\text {Public+Financial }}$.

We also identify export-intensive companies as those operating in tradables sectors according to the classification scheme by Mian and Sufi (2014) and create the variable $\mathbb{1}_{\text {Tradable }}$ which takes the value 1 if a firm is in a tradable industry and 0 otherwise.

\footnotetext{
${ }^{12}$ These indexes are the BVC Capitalization, Prage SE, Mexico IPC (Bolsa), Nigeria All Share, Romania BET and FTSE/JSE All Share for Colombia, Czech Republic, Mexico, Nigeria, Romania and South Africa, respectively.

${ }^{13}$ Firms are state owned if a majority of their stock (more than $50 \%$ ) is owned by the government
} 
Another important variables that we use in our empirical analysis is the measure of financial constraints, or external financial dependence. We compute it following Rajan and Zingales (1998) as capital expenditures minus cash flows from operations over capital expenditures, using balance sheet data relative to the year preceding the shock. We denote this variable $E F D_{i}$.

We are also interested in whether firms access corporate debt markets and whether they are owned by foreigners. For that, search Thomson Reuters SDC Platinum to identify companies in our sample that issue corporate debt in the last five years (over our sample period) and create the indicator variable $\mathbb{1}_{\text {CorpDebt }}$ accordingly. To disentangle between companies with larger and smaller foreign ownership, we exploit the list of companies in the MSCI Emerging Markets index, that we get from the MSCI website. Since these companies are usually the ones mostly traded by foreign investors, our proxy for $\mathbb{1}_{\text {ForOwnership }}$ is therefore a dummy that takes the value of one if a company belongs to this list in the quarter preceding the shock and zero otherwise.

\subsection{Sovereign Debt Inflows, Exchange Rates, and Sovereign Bond Yields}

One of our main predictions is that, an increased demand of local currency sovereign debt by foreigners - as the one produced by the country's inclusion into an index - produces an increase in the price of sovereign bonds and, therefore, a reduction in sovereign debt yields. We test for this prediction in our data by looking at the time series of the 5 -year government bond yields of affected countries around the announcement dates. Figure 4 depicts the time series of the 5-year government bond yield for each of the countries, separately. It is clear from this figure that government yields drop sharply when index providers make their announcements about a country's inclusion in the benchmark. The figure not only provides evidence in favor of our first, important transmission mechanism, but also lends important support to our identifying assumption that announcement dates were unexpected. Indeed, it is clear from the figure that there are no common pre-announcement trends in government bond yields across affected countries. In most cases, government bond yields are quite stable before the announcement dates, and then they sharply decrease precisely when index providers announce the inclusion event. 
Our second main prediction is that, sovereign debt inflow shocks produce also an appreciation of the domestic currency because of the increased demand of local currency by foreigners and the frictions in the exchange rate market. This is indeed what happens in five of the six countries in our sample, as depicted in Figure 5 where we report the time series of the exchange rate for each of the countries, separately. The exchange rate in the figure is the amount of local currency needed to buy one US dollar, so that the drop in the announcement date represents an appreciation of the local currency. The appreciation is not as sharp as the drop in the yields, which can be explained by the fact that exchange rates are much less stable than government bond yields, even in calm periods. What is important to note is that, as for the sovereign bond yields, there are no clear pre-announcement trend common to the six countries.

To quantitatively assess the economic magnitude of these two effects, we compare the 2-day log changes in sovereign bond yields and exchange rates in each country after the announcement with the country-specific average 2-day log changes computed in a 2-year window around the announcement date. Figure 6 and Figure 7 provide a graphical representation of the results. In both cases, the change at the announcement date lies in one of the tails of the distribution of 2-day changes. In Table 1 we show also that changes in sovereign bond yields and exchange rates in the two days following the announcement are statistically different from the average 2-day changes in government bond yields and log exchange rate computed in a window of +-360 trading days. For all the countries and shocks except one, the 2-day changes following the announcement are significantly different from the sample mean around this window. The only exception is the Nigerian exchange rate, which does not experience an appreciation in the two days after the announcement. However, it is worth noticing that this country had a managed exchange rate system at the time so that the monetary authority might have tried to prevent the appreciation in the domestic currency.

Hence, as hypothesized, the large and unexpected inflows to the sovereign debt markets of newly included countries significantly affect two key macroeconomic variables. In light of these two first order effects, we expect sovereign debt inflow shocks to have a differential effect on domestic firms, depending on their sensitivity to changes in either the sovereign bond yield or the exchange rate. We test this in the next section. 


\section{The Effects of Sovereign Debt Inflows on Domestic Firms: an Event Study}

Under the identifying assumptions described in 2 , we can measure the effect that sovereign debt inflow shocks have on domestic firms by conducting a multiple event study around the announcement dates. Under the efficient market hypothesis, stock prices of domestic firms should respond to changes in the profitability of firms immediately after the announcement. Thus, we look at the cumulative abnormal returns of domestic firms in the two days following the announcement date. Then, we can assess both the overall effect of sovereign debt inflow shocks on the economy of the recipient country, and the effect on specific subgroups of firms which should be more or less affected to either the sovereign bond yield and the exchange rate.

We compute cumulative abnormal returns for listed domestic firms in four different ways. First, we compute, for each firm, the daily cumulative abnormal returns as the difference between the returns and the average daily return in the previous year. We define such de-trended return as $C A R_{i}^{\text {Average }}{ }^{14}$ For that, we compute the average in the 252 trading days before $t-10$, where $t$ is the announcement of the rebalancing for each country. Second, we compute firms' cumulative abnormal returns as the returns that exceed the predicted price increase using a 1-factor model, the risk premium on a regional factor (the MSCI EM Index). We label such cumulative abnormal returns as $C A R_{i}^{1-F a c t o r}{ }^{15}$ Third, we use a 2-factor model that includes, on top of the regional factor, a global factor (the MSCI World Index), to compute $C A R_{i}^{2-F a c t o r}$. Fourth, we calculate a 5-factor model that adds the small minus big (SMB), high minus low (HML), and momentum (WML) factors. We label these cumulative abnormal returns $C A R_{i}^{5 \text {-Factor }}{ }^{16}$ For all of these models, we compute the 2-day cumulative abnormal returns after the rebalancing date for each country, and

\footnotetext{
${ }^{14}$ Our results are quantitatively similar when we use excess returns, as stock market returns minus the risk-free rate divided by the 252 trading days in a year. WE SHOULD ADD STH ABOUT WHY NOT RISK FREE RATE.

${ }^{15}$ We estimate the model over the interval of time that goes from 252 trading days prior to the announcement date to 10 trading days before the announcement date.

${ }^{16}$ These factors are computed for each country following Cakici et al. (2013).
} 
use it as our main dependent variable. ${ }^{1718}$

\subsection{Overall Effect of Sovereign Debt Inflow Shocks}

To assess the overall effect of sovereign debt inflows shocks on firms in the recipient countries we look at the average 2-day cumulative abnormal returns after the announcement date in each country. The average is computed over the entire population of domestic firms in our dataset, as:

$$
\overline{C A R}=\frac{\sum_{i}^{I} C A R_{i}}{I}
$$

In this first specification, we test whether these returns are significantly different from zero. The results are reported in Table 2, Panel A. In each column we consider a different measure of cumulative abnormal returns. The simplest one, the de-trended returns, show average returns that are positive but not significantly different from 0 following the announcement dates. $C A R$ computed using different models are also positive on average - they range from $0.13 \%$ to $0.18 \%$ but not statistically distinguishable from zero. To validate our exercise, we also report in Panel B the $C A R$ from $t-3$ to $t-1$. Under the hypothesis that the announcement dates are not anticipated, $C A R$ should not be statistically different from 0 in the days before the announcement. We show that this is indeed the case as in this case the average 2-day cumulative abnormal returns is very close to zero in 3 of the 4 columns $(-0.002,-0.008$, and 0.033$)$ and well below the significance level.

From Table 2 our results suggest that capital inflows to the sovereign debt market have little or no overall effect on firms' stock market returns. However, this result masks important heterogeneity across firms, as we show in the next subsection.

\footnotetext{
${ }^{17}$ We follow a similar strategy to that of Alfaro et al. (2017) that analyze stock market returns in a 2-day period after the announcement of capital controls for Brazil. Results from our main estimated coefficients are very similar when we use 3-6 day windows highlighted in Appendix Figure A.1. The only difference is that the standard errors widen in windows larger than 4 days after the announcement date.

${ }^{18}$ Additionally, for each of the models, we drop 2-day CAR above and below the 1st and 99th percentile to control for outliers.
} 


\subsection{Heterogeneous Effects of Sovereign Debt Inflow Shocks}

According to the transmission mechanisms we discuss in Section 2.1, firms in the recipient countries should be differentially affected depending on the sensitivity to sovereign bond yield and exchange rate. In particular, firms who are more sensitive to the reduction in sovereign bond yields might benefit from the capital inflow shocks, while exporting firms might be damaged by the same event. Here we test for this hypothesis by estimating the following equation

$$
C A R_{i}=\theta_{c}+\alpha_{1} \mathbb{1}_{\text {Tradable }}+\alpha_{2} \mathbb{1}_{\text {Public }+ \text { Financial }}+\alpha_{3} E F D_{i}+\varepsilon_{i}
$$

where $\theta_{c}$ are country fixed effects. $\mathbb{1}_{\text {Tradable }}$ is a dummy variable indicating whether a firm belongs to a tradable industry or not. $\mathbb{1}_{\text {Public+Financial }}$ is a dummy variable indicating whether a firm has connections to the government, or is a financial firm. $E F D_{i}$ is a measure of financial constraints, or external financial dependence for firm $i$ and $\varepsilon_{i}$ is the error term. This specification allows us to capture how different firms respond to capital inflows to the sovereign debt market. For example, $\alpha_{1}$ captures the average cumulative abnormal returns of tradable firms relative to the rest of the firms in the economy (that are not government related or financial firms).

Before looking into the full specification, we consider only the direct effects on tradable and government related and financial firms with no fixed effects. Results from this analysis are reported in Table 3. They show results which are consistent with the hypothesized transmission channels. Public and financial firms experience positive abnormal returns that are statistically significant under all $C A R$ models. In our preferred specification (2-factor model), these returns 0.595 percentage points larger than the average cumulative returns. ${ }^{19}$ At the same time, tradable firms experience negative abnormal in the 2 days following the announcement dates. However, these are not statistically different from zero, but the point estimate is large in absolute value, 0.41 percentage points lower than the average cumulative abnormal returns. We also perform placebo estimations on these heterogeneous effects (Panel B). In all the $C A R$ models, these heterogeneous effects are

\footnotetext{
${ }^{19}$ While the 5-factor model adds more factors, these additional factors are estimated with few firms which may add instability to this model, and thus we prefer the 2-factor model, with a regional and global factor.
} 
not significantly different from zero. Additionally, the actual coefficients are, in absolute size, much smaller than the ones in Panel A.

Another important prediction from our model is that, given that financial institutions experience a positive shock, they could increase credit to firms in the economy. This effect could differentially affect firms according to their needs of external financing. Firms that are more dependent on this financing, should experience higher returns. To test this, in Table 4, we add our external financial dependence variable, External $\mathrm{FD}_{i}$ to the previous specification. ${ }^{20}$ The results show that indeed firms with larger external financial dependence experience higher abnormal returns after the announcement date (Panel A). Quantitatively, a one-standard deviation increase in external financial dependence leads to returns that are 0.15 percentage points higher. Additionally, we also observe that the inclusion of this variable, improves the estimation of the negative effect on tradable firms, which is now negative and statistically different from zero.

\subsection{Exploiting Within and Cross-Country Variation}

Up until now, we have only exploited variation across firms, pooling companies in all countries together. To exploit better the variation within countries, we start by including country fixed effects and estimating Equation (2) in Table 5. This allows us to compare the heterogeneous effects of capital inflows on firms within each country. More specifically, the country fixed effects absorb the average cumulative abnormal returns for each country. Results are quantitatively and qualitatively similar to the ones in Table 4 (Panel A). Also, importantly for our identification strategy, these heterogeneous effects are not present before the announcement date (Panel B), where all the coefficients are not significantly different from zero, and much smaller in absolute size.

While Equation (2) allows us to identify the heterogeneous effects on firms of capital inflows, it does not exploit the full cross-country variation in the data. More specifically, it does not use the actual changes in government bond yields and exchange rates that vary across countries. To fully

\footnotetext{
${ }^{20}$ We compute this variable at the firm level. Results are qualitatively similar, though we lose some precision, when using the same measure but at the industry level (Appendix Table A.3).
} 
exploit this, and have quantitative implications for changes in yields and the exchange rate, we use the following framework:

$$
C A R_{i}=\theta_{c}+\beta_{1} \mathbb{1}_{\text {Tradable }} S_{c}^{E R}+\beta_{2} \mathbb{1}_{\text {Public }+ \text { Financial }} S_{c}^{Y i e l d}+\beta_{3} E F D_{i} S_{c}^{Y i e l d}+\varepsilon_{i}
$$

where we now have the same indicator and financial constraints variables as in Equation (2), but now interacted with two terms: $S_{c}^{E R}$ and $S_{c}^{Y i e l d}$. These are, respectively, the 2-day change in the log exchange rate and 5-year government bond yield after the announcement date (shock variables) each multiplied by -1 to normalize shocks. $\varepsilon_{i}$ is an error term.

Under this specification, $\beta_{1}$ captures the relationship across countries between the difference in the shock and the differential cumulative abnormal returns between tradable firms and a control group (non-financial, non-government related and non-tradable firms). We can show this with a very simple example. Notice that,

$$
\begin{gathered}
{\left[C A R_{i} \mid \mathbb{1}_{\text {Tradable }}=0, c=C O\right]=\theta_{C O}} \\
{\left[C A R_{i} \mid \mathbb{1}_{\text {Tradable }}=1, c=C O\right]=\beta_{1} S_{C O}^{E R}+\theta_{C O}} \\
{\left[C A R_{i} \mid \mathbb{1}_{\text {Tradable }}=0, c=M X\right]=\theta_{M X}} \\
{\left[C A R_{i} \mid \mathbb{1}_{\text {Tradable }}=1, c=M X\right]=\beta_{1} S_{M X}^{E R}+\theta_{M X}}
\end{gathered}
$$

where $c=C O$ and $c=M X$ indicates the countries in the example being Colombia and Mexico, respectively. Then, we can compute the expected differential returns between tradable firms and the control group within countries:

$$
\begin{gathered}
{\left[C A R_{i} \mid \mathbb{1}_{\text {Tradable }}=1, c=C O\right]-\left[C A R_{i} \mid \mathbb{1}_{\text {Tradable }}=0, c=C O\right]=\beta_{1} S_{C O}^{E R}} \\
{\left[C A R_{i} \mid \mathbb{1}_{\text {Tradable }}=1, c=M X\right]-\left[C A R_{i} \mid \mathbb{1}_{\text {Tradable }}=0, c=M X\right]=\beta_{1} S_{M X}^{E R}}
\end{gathered}
$$


Next, we can take the difference between 8 and 9 to get

$$
\frac{\left(C A R_{i, T, C O}-C A R_{i, C, C O}\right)-\left(C A R_{i, T, M X}-C A R_{i, C, M X}\right)}{S_{C O}^{E R}-S_{M X}^{E R}}=\beta_{1}
$$

where $C A R_{i, j, c}$ is the cumulative abnormal returns of firm $i$ in industry group $j$ and country $c$. Thus, $\beta_{1}$ shows the relationship across countries between the shocks to the exchange rate and the differential cumulative returns of tradable and control firms. Similarly, $\beta_{2}$ indicates the relationship across countries between the shocks to the government bond yield and the differential cumulative returns of government related and financial firms and control firms.

Figure 8 provides a graphical representation of the results. In it, we plot the $\beta$ coefficient of $\mathbb{1}_{\text {Tradable }}$ and $\mathbb{1}_{\mathrm{P}+\mathrm{F}}$ for each country as a function of the country-specific 2-day change in the sovereign yield and log exchange rate. This figure shows that the intensity of the exchange rate and government bond yield shocks is related with the respective heterogeneous channels for firms.

The findings in Table 6 - in which we report the estimated coefficient of Eq. (3) are both quantitatively and qualitatively similar to our previous estimation but now we can draw more specific quantitative implications. Capital inflows to sovereign debt markets that lead to a 100 basis points reduction in the 5 -year government bond yield lead to cumulative abnormal returns higher by 1.8 percentage points for financial and government related firms relative to the rest of the firms in the economy. In turn, capital inflows that lead to a $1 \%$ appreciation of the exchange rate, have a negative effect of 0.42 percentage points for tradable firms relative to the rest of the companies in the country. Moreover, a 100 basis points reduction in government bond yields leads to stock market returns 0.7 percentage points higher for firms in the 75th percentile of the distribution of external financial dependence when compared to firms in the 25 th percentile of external financial dependence. 


\section{Threats to Identification, Robustness and Discussion}

\subsection{Threats to Identification}

Our empirical strategy relies on a key assumption. That is, the only way the announcement of countries inclusion by index providers affect stock prices is through an increased demand of local currency denominated sovereign debt by foreign investors. This demand affects the yield and the exchange rate and therefore propagates to firms, having differential effects depending on firms' exposure to changes in each of the two variables.

As already discussed in Section 2.4, the absence of systematic patterns in sovereign bond yields in the pre-announcement period and the lack of news about important policy changes in the period around the announcement provide important support to validate the assumption. However, one could still be concerned that the events we look at do not only trigger capital inflows to the sovereign debt market of affected countries but also reveal information about the fundamentals of either the country or their sovereign debt or the reputation of the government. In principle, if index providers were basing their inclusion decision on some information they have about the economic prospects of countries, the announcement of a country's inclusion might convey this information to the market. If the underlying reason for the inclusion is likely to affect firms as well as to attract foreign investors, we could not argue that the estimated effect we document is to be attributed to the causal impact of sovereign inflow shocks. Since we are not looking at firms but rather at countries, it seems very unlikely that international investors have no access to the information on which index providers base their inclusion decision. Still, it could be that the technology available to index providers is superior and investors have limited information collection capacity. If this was true, one should expect capital inflows to increase not only for sovereign debt, but also for asset classes such corporate debt, equity, and foreign direct investment. In Figure 9, we plot the sovereign and private inflows. Private inflows are composed of portfolio debt, equity and foreign direct investment inflows. We present the median across countries for these variables for the 3 years

previous to the year of the announcement and for the year of the announcement. ${ }^{21}$ Sovereign inflows

\footnotetext{
${ }^{21}$ We present the country-by-country figures in Appendix Figure A.2.
} 
nearly triple in the announcement year compared to previous years. However, private inflows only increase very slightly. This is suggestive that the announcement of these events do not appear to be conveying new information about the economic prospects of the country.

The evidence presented thus far does not rule out that the announcements convey information about the reputation of the government, thus reducing the expected default probability of a country. In that case, the interpretation would be different, as the reduction in yields could be driven not by capital inflows, but rather by changes in the probability of default of the government. To rule this out, we look at the time series evolution of 5-year local currency government bond yields and also of the J.P. Morgan EMBI foreign currency sovereign spreads. In Figure 10, we plot an index for these variables that equals 100 for the day previous to the announcement date. ${ }^{22}$ The index is constructed by using the average log change in both variables across countries. Since the announcement date, local currency government bond yields fall significantly, close to 10 percent 20 days after the announcement date. Conversely, foreign currency sovereign spreads are relatively stable since the announcement date, even increasing slightly 20 days after the announcement date. If anything, the effect of the announcement date is much sharper for local currency than foreign currency yields. This is very suggestive that even if there is a slight decrease in the probability of default of the government, this cannot explain the whole large decrease in local currency government bond yields.

\subsection{Robustness}

We conduct several robustness tests. First, we analyze whether other potential channels are at play during episodes of higher expected capital inflows to the sovereign debt market. For example, firms that access corporate debt or syndicated loan markets could have positive spillovers from reductions in government bond yields as highlighted in Dittmar (2008). To explore this channel we add $\mathbb{1}_{\text {Intl.Mkt Access }}$ into our previous specification. Furthermore, we analyze whether firms that are more likely to be owned by foreigners experienced higher abnormal returns after the announcement

\footnotetext{
${ }^{22}$ We present the country-by-country figures in Appendix Figure A.3. While foreign currency sovereign spreads vary a lot, and without any significant pattern, local currency government bond yields fall for every country.
} 


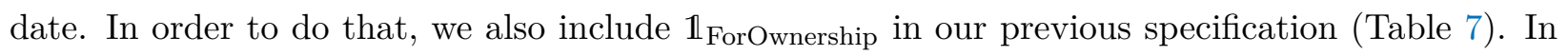
our preferred 2-factor model, these channels have a positive coefficient with a large point estimate, but that are not statistically different from zero. One possibility is that there are not too many firms that access international markets, or are included in MSCI indexes for these countries. Additionally, the inclusion of these variables do not seem to affect the channels described above, with coefficients that are still statistically significant and of similar magnitude to those in Table 6.

Second, we also control for the size of firms in Table 8. This reduces our number of observations somewhat, but does not affect the results in our main specification. Third, in Table 9 we consider also firms that belong to the affected countries but have stocks that are quoted in foreign markets. ${ }^{23}$ Our findings are qualitatively similar to our main specification, albeit with the result on external financial dependence being statistically significant only in two $C A R$ models.

\subsection{FIR Size and Heterogeneity of Shocks}

In this section we discuss the potential drivers of the heterogeneity in the country shocks. To start, we relate the change in the yields and log exchange rate to the measure of FIR discussed in Section 2.2. We display this relationship in Figure 11. As expected, for government bond yields, a larger FIR is associated with a larger drop in yields. One noticeable outlier is Czech Republic, where the FIR is moderately large, but there is almost no change in the yield due to the fact that yields were close to zero. This suggests that FIR interacts with other pre-conditions of the country for the observed change in the yield. In the exchange rate, we do not observe this relationship with FIR. In fact, a larger FIR is associated with a smaller local currency appreciation. Notice that, in general, exchange rate are more volatile, and the central bank might interven in the foreign exchange market to change the potential effect of FIR on the exchange rate. This is evident in the case of Nigeria which had a tightly managed exchange rate policy during the time of the upgrade. Additionally, countries that were experiencing large appreciations in the months before the announcement, such as Czech Republic, Nigeria, and Romania, had smaller appreciations in

\footnotetext{
${ }^{23}$ For the returns of these stocks, we appropiately adjust them with the exchange rate.
} 
the day after the announcement. This is contrary to the case of Colombia and South Africa, where the local currency was depreciation previous to the announcement date, and experienced large appreciations right after the announcement. Thus, one potential explanation for the heterogeneity of countries regarding the exchange rate, is the interaction between the announcement and the previous depreciation/appreciation rate of the domestic currency. In countries with large previous appreciations, there might not be much more room for large appreciations after the announcement. And in countries with large previous depreciations, the announcement might mean a break in the tendency.

\section{Conclusions}

In this paper we empirically explore the transmission channels from capital inflows to sovereign debt markets for firms in the economy. In the classical theoretical model of a small open economy, these inflows have no role in affecting macroeconomic variables, and thus firms in the economy.

To test this, we use countries' inclusions into well-known local currency sovereign debt market indexes as shocks to capital inflows into these markets. These events convey little information about the future economic prospects of countries but induce large capital flows from institutional investors tracking the indexes. We show that inclusion-driven flows significantly reduce government bond yields and appreciate the domestic currency.

We use an event study methodology in the two days following the announcement of these country inclusions to analyze how it affects firms in the economy. Our findings show that these inflows have heterogenous impact on firms' stock market returns. Government related firms, financial firms and firms with larger financial constraints experience positive abnormal returns in the two days following the announcement of these events. Instead, companies operating in tradable sectors have negative abnormal returns.

Our findings shed novel light on the channels through which capital inflows to sovereign debt markets affect firms in the economy. Furthermore, our results suggest that foreign demand shocks 
in sovereign debt markets should be incorporated into small open economy models. 


\section{References}

Alfaro, L., Chari, A., Kanczuk, F., 2017. The real effects of capital controls: Firm-level evidence from a policy experiment. Journal of International Economics 108, 191-210.

Alfaro, L., Kalemli-Ozcan, S., Volosovych, V., 2014. Sovereigns, Upstream Capital Flows, And Global Imbalances. Journal of the European Economic Association 12, 1240-1284.

Altavilla, C., Pagano, M., Simonelli, S., 2017. Bank Exposures and Sovereign Stress Transmission. Review of Finance 21, 2103-2139.

Andrade, S. C., Chhaochharia, V., 2018. The costs of sovereign default: Evidence from the stock market. The Review of Financial Studies 31, 1707-1751.

Arslanalp, S., Tsuda, T., 2014. Tracking Global Demand for Emerging Market Sovereign Debt. IMF Working Papers 14/39, International Monetary Fund.

Baskaya, Y. S., di Giovanni, J., Kalemli-Ozcan, S., Peydro, J.-L., Ulu, M. F., 2017. Capital flows and the international credit channel. Journal of International Economics 108, 15-22.

Baskaya, Y. S., Kalemli-Ozcan, S., 2016. Sovereign risk and bank lending: Evidence from 1999 turkish earthquake. Working Paper 22335, National Bureau of Economic Research.

Becker, B., Ivashina, V., 2018. Financial repression in the european sovereign debt crisis. Review of Finance 22, 83-115.

Benigno, G., Converse, N., Fornaro, L., 2015. Large capital inflows, sectoral allocation, and economic performance. Journal of International Money and Finance 55, 60-87.

Blanchard, O., Ostry, J. D., Ghosh, A. R., Chamon, M., 2017. Are Capital Inflows Expansionary or Contractionary? Theory, Policy Implications, and Some Evidence. IMF Economic Review 65, $563-585$.

Bolton, P., Jeanne, O., 2011. Sovereign Default Risk and Bank Fragility in Financially Integrated Economies. IMF Economic Review 59, 162-194. 
Broner, F., Erce, A., Martin, A., Ventura, J., 2014. Sovereign debt markets in turbulent times: Creditor discrimination and crowding-out effects. Journal of Monetary Economics 61, 114-142.

Cakici, N., Fabozzi, F. J., Tan, S., 2013. Size, value, and momentum in emerging market stock returns. Emerging Markets Review 16, 46-65.

Calomiris, C. W., Larrain, M., Schmukler, S. L., 2018. Capital Inflows, Equity Issuance Activity, and Corporate Investment. NBER Working Papers 24433, National Bureau of Economic Research, Inc.

Chari, A., Blair Henry, P., 2008. Firm-specific information and the efficiency of investment. Journal of Financial Economics 87, 636-655.

Chari, A., Henry, P. B., 2004. Risk Sharing and Asset Prices: Evidence from a Natural Experiment. Journal of Finance 59, 1295-1324.

Chari, A., Leary, R., Phan, T., 2018. The Costs of (sub)Sovereign Default Risk: Evidence from Puerto Rico. Working Paper 18-3, Federal Reserve Bank of Richmond.

Cremers, M., Ferreira, M. A., Matos, P., Starks, L., 2016. Indexing and Active Fund Management: International Evidence. Journal of Financial Economics 120, 539-560.

Dittmar, R. F., 2008. Do Sovereign Bonds Benefit Corporate Bonds in Emerging Markets? Review of Financial Studies 21, 1983-2014.

Gabaix, X., Maggiori, M., 2015. International Liquidity and Exchange Rate Dynamics. The Quarterly Journal of Economics 130, 1369-1420.

Gennaioli, N., Martin, A., Rossi, S., 2014. Sovereign Default, Domestic Banks, and Financial Institutions. Journal of Finance 69, 819-866.

Gennaioli, N., Martin, A., Rossi, S., 2018. Banks, government Bonds, and Default: What do the data Say? Journal of Monetary Economics 98, 98-113.

Greenwood, R., Vayanos, D., 2010. Price Pressure in the Government Bond Market. American Economic Review 100, 585-590. 
Hébert, B., Schreger, J., 2017. The Costs of Sovereign Default: Evidence from Argentina. American Economic Review 107, 3119-3145.

Kohn, D., 2017. Addicted to Debt: Foreign Purchases of U.S. Treasuries and the Term Premium. Tech. rep.

Krishnamurthy, A., Nagel, S., Vissing-Jorgensen, A., 2017. ECB Policies Involving Government Bond Purchases: Impact and Channels. NBER Working Papers 23985, National Bureau of Economic Research, Inc.

Krishnamurthy, A., Vissing-Jorgensen, A., 2011. The Effects of Quantitative Easing on Interest Rates: Channels and Implications for Policy. Brookings Papers on Economic Activity 42, 215287.

Lane, P. R., McQuade, P., 2014. Domestic credit growth and international capital flows. The Scandinavian Journal of Economics 116, 218-252.

Larrain, M., 2015. Capital Account Opening and Wage Inequality. Review of Financial Studies 28, $1555-1587$.

Mian, A., Sufi, A., 2014. What Explains the 2007-2009 Drop in Employment? Econometrica 82, $2197-2223$.

Ongena, S., Popov, A., Horen, N. V., 2019. The Invisible Hand of the Government: Moral Suasion during the European Sovereign Debt Crisis. American Economic Journal: Macroeconomics 11, $346-379$.

Pandolfi, L., Williams, T., 2019. Capital Flows and Sovereign Debt Markets: Evidence from Index Rebalancings. Journal of Financial Economics 132, 384-403.

Perez, D. J., 2015. Sovereign Debt, Domestic Banks and the Provision of Public Liquidity. Discussion Papers 15-016, Stanford Institute for Economic Policy Research.

Raddatz, C., Schmukler, S., Williams, T., 2017. International Asset Allocations and Capital Flows: The Benchmark Effect. Journal of International Economics 108, 413-430. 
Rajan, R. G., Zingales, L., 1998. Financial Dependence and Growth. American Economic Review $88,559-586$.

Schnabl, P., 2012. The International Transmission of Bank Liquidity Shocks: Evidence from an Emerging Market. The Journal of Finance 67, 897-932.

Vayanos, D., Vila, J.-L., 2009. A Preferred-Habitat Model of the Term Structure of Interest Rates. CEPR Discussion Papers 7547, C.E.P.R. Discussion Papers.

Warnock, F., Warnock, V., 2009. International Capital Flows and U.S. Interest Rates. Journal of International Money and Finance 28, 903-919.

Williams, T., 2018. Capital inflows, sovereign debt and bank lending: Micro-evidence from an emerging market. Review of Financial Studies 31, 4958-4994. 
Figure 1: Emerging Market Sovereign Debt held by Foreign Investors

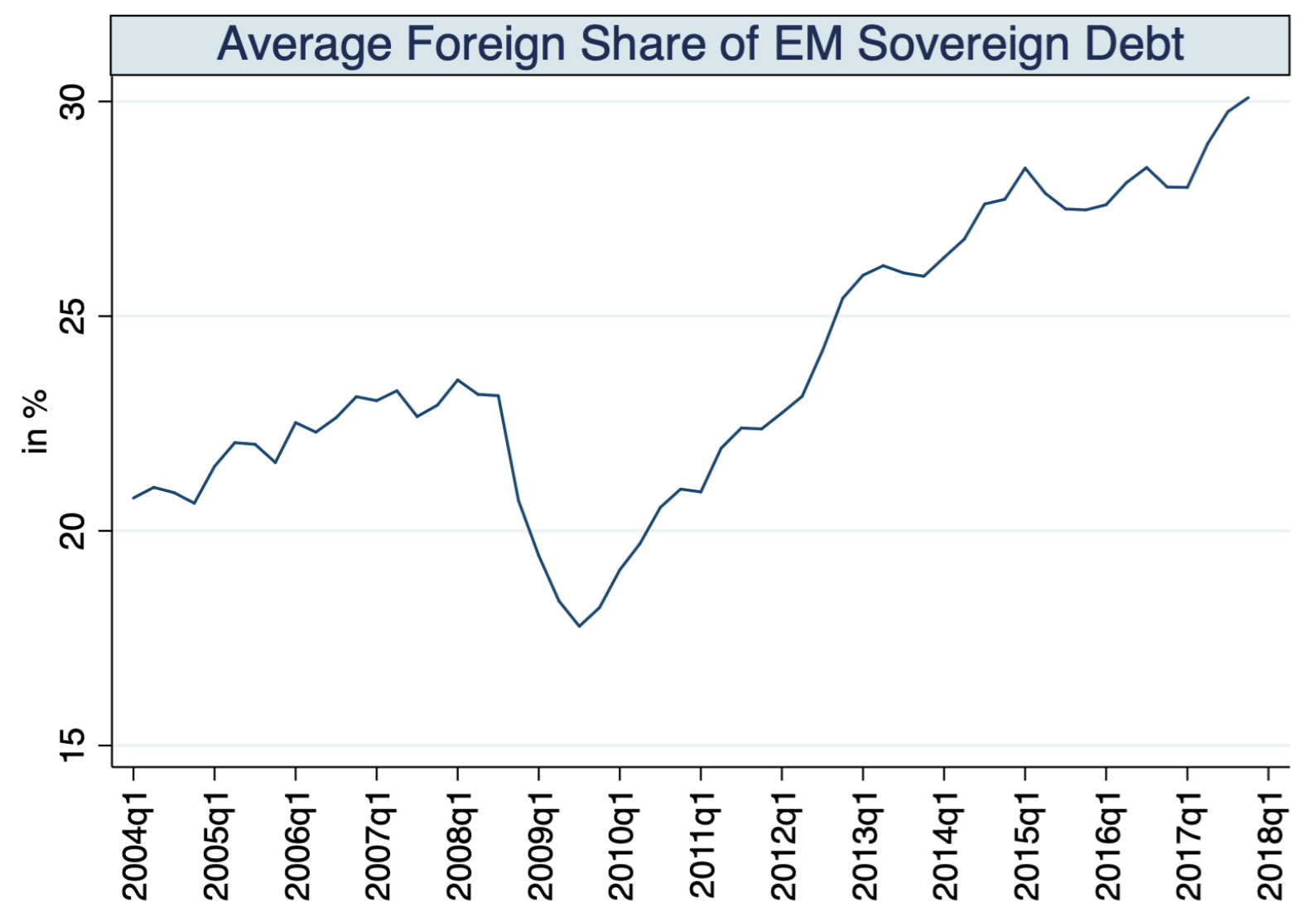

Note: This figure shows the average foreign share of sovereign debt for emerging markets. It is computed as the sovereign debt held by foreign private investors, divided by the total sovereign debt for each country, and then averaged across country at each point in time. The data on the holders of government debt is from Arslanalp and Tsuda (2014). 
Figure 2: Cumulative Abnormal Returns for Different Firms

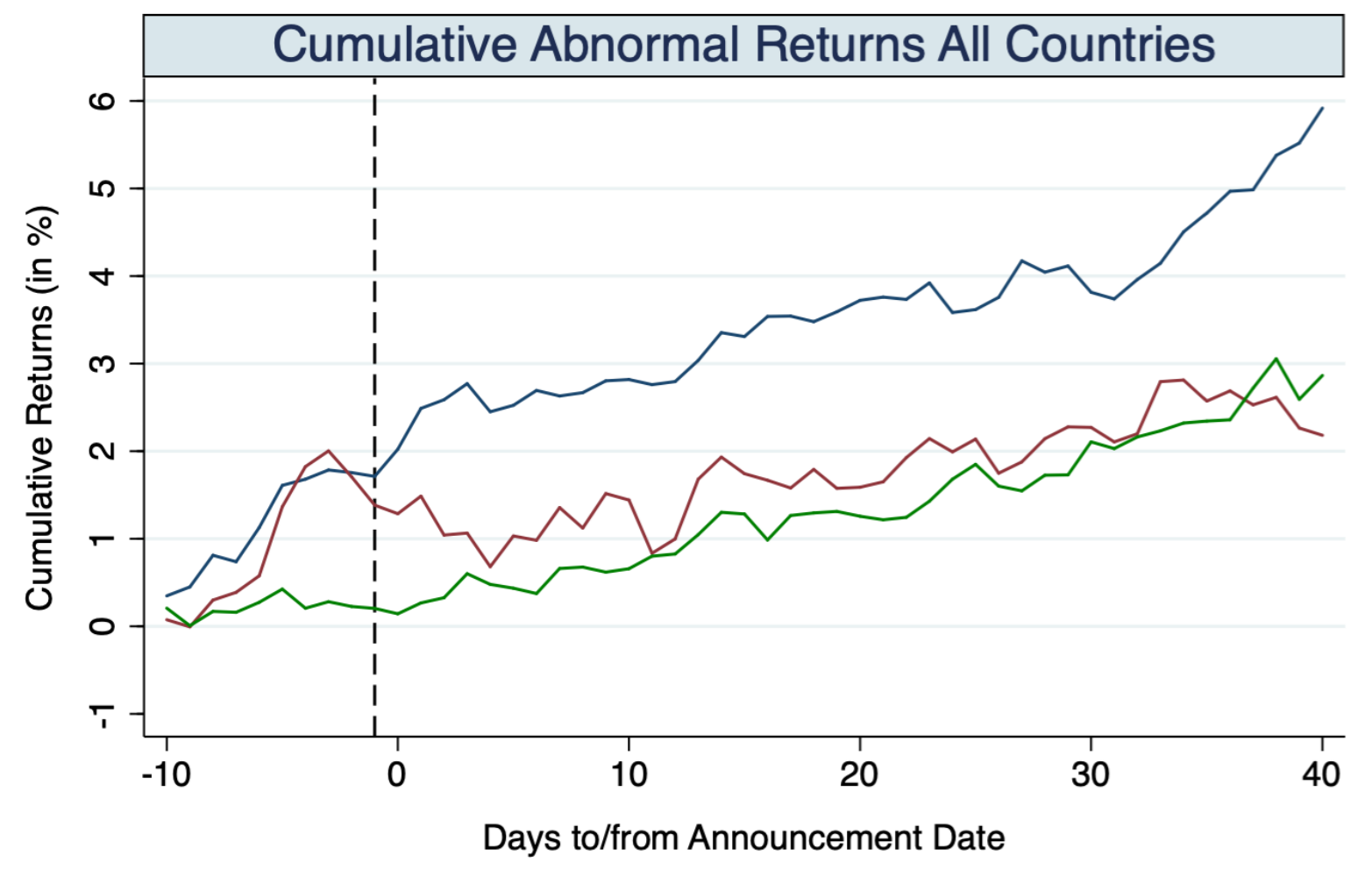

Public+Financial

Tradable

Rest

Note: This figure displays the average cumulative abnormal returns (in percentage) for all firms in our sample. It starts 15 trading days previous to the announcement date, and ends 40 trading days after the announcement date. We divide the sample into government related+financial firms, firms in tradable industries, and the rest of firms in the economy. Cumulative abnormal returns are computed using the 3 -factor model $\left(C A R_{i}^{3-F a c t o r}\right)$ which includes the domestic stock market as the local factor, a regional factor (the MSCI Emerging Markets Index), and a global factor (the MSCI World Index). 
Figure 3: Private Foreign Share of Government Debt around Events

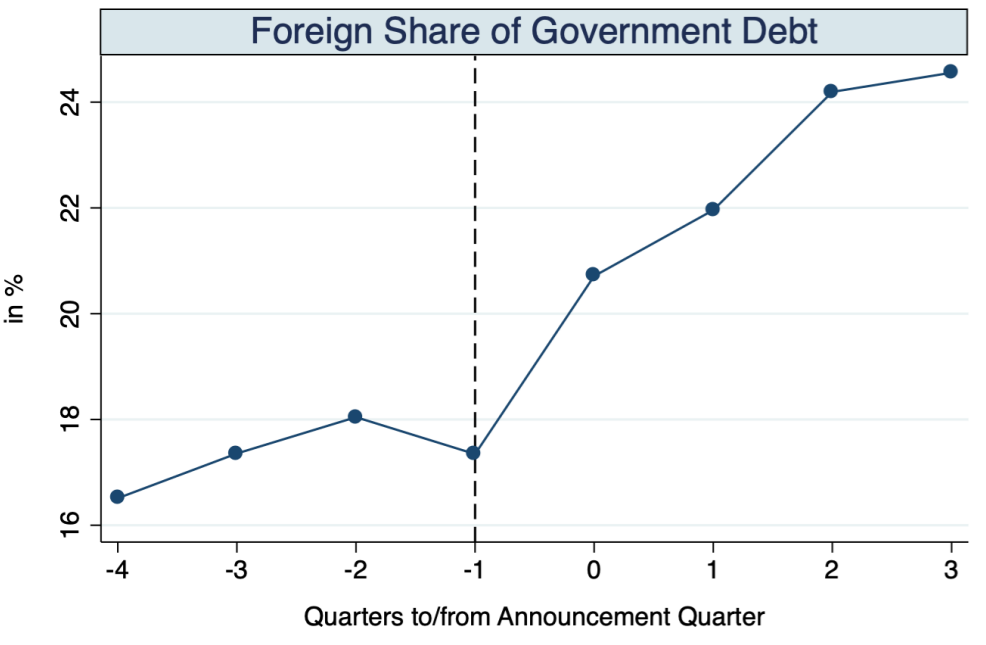

Median Private Foreign Share of Government Debt

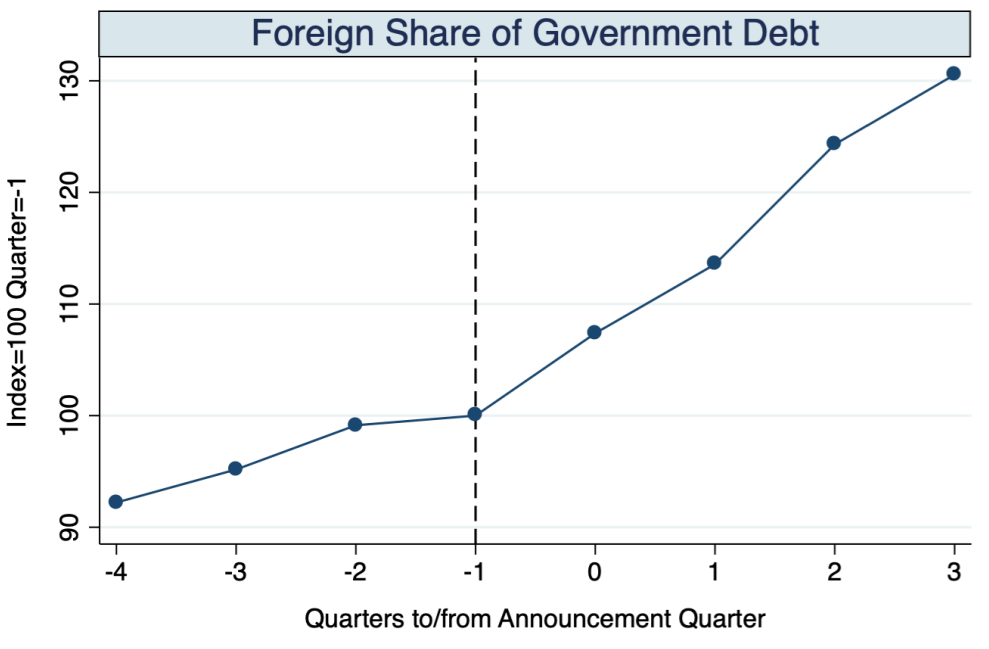

Index Median Growth Foreign Share of Government Debt

Median Private Foreign Share of Government Debt

Note: This figure displays the foreign share of government debt for Colombia, Czech Republic, Mexico, Nigeria, Romania and South Africa around the announcement date of the rebalancings. The quarter equal to minus one is the quarter previous to the announcement date. The left panel is the median average foreign share for these countries. The right panel is an index equal to 100 for the quarter before the announcement date and is constructed using the median growth rate of the private foreign share of government debt for these countries. The data on the private foreign holders of government debt is from Arslanalp and Tsuda (2014). 
Figure 4: Time Series 5Y Government Bond Yield

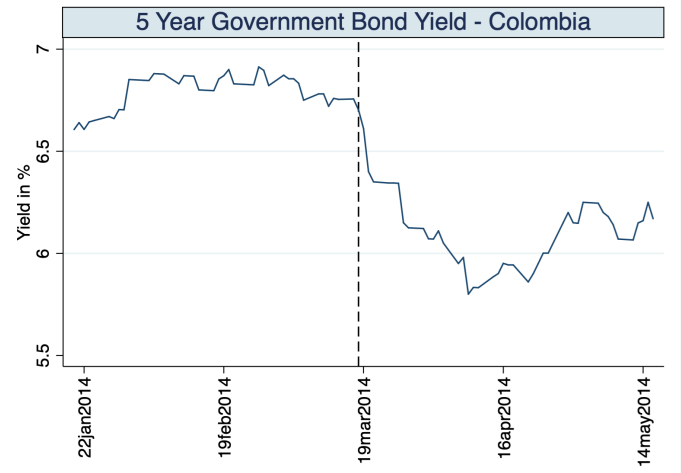

Colombia

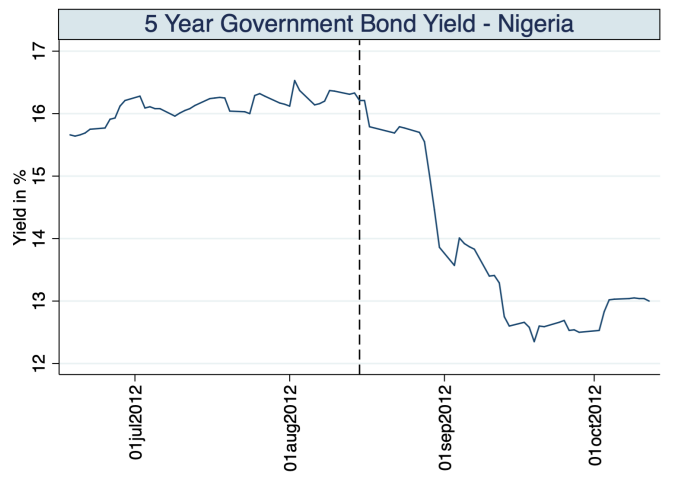

Nigeria

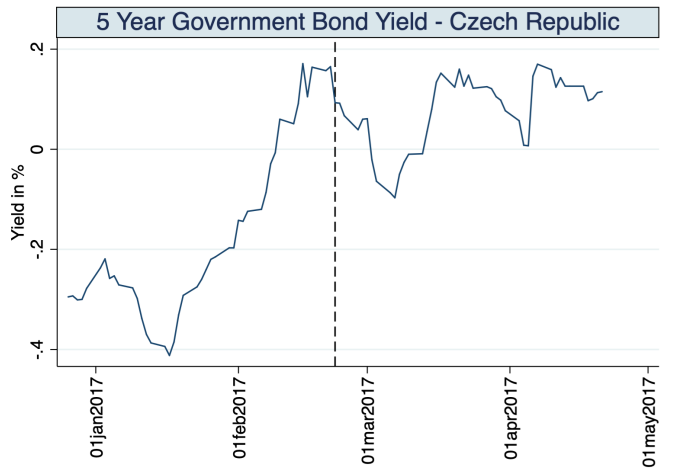

Czech Republic

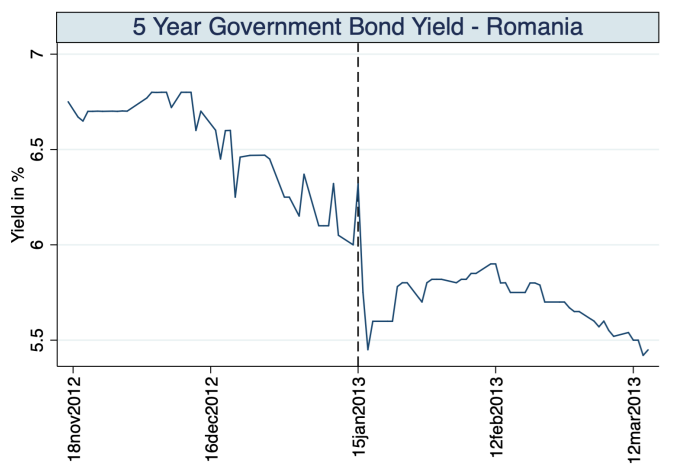

Romania

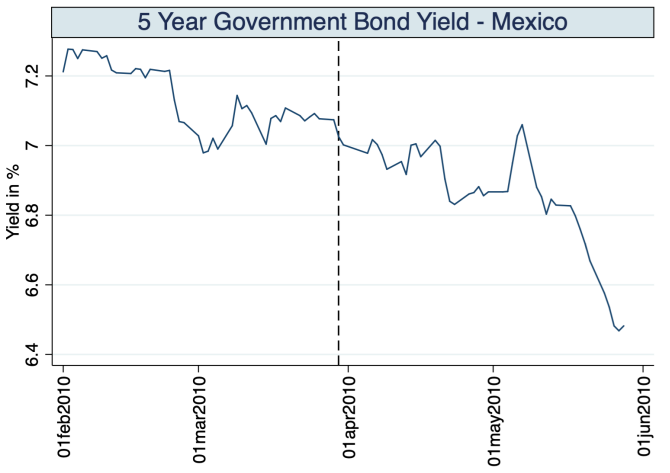

Mexico

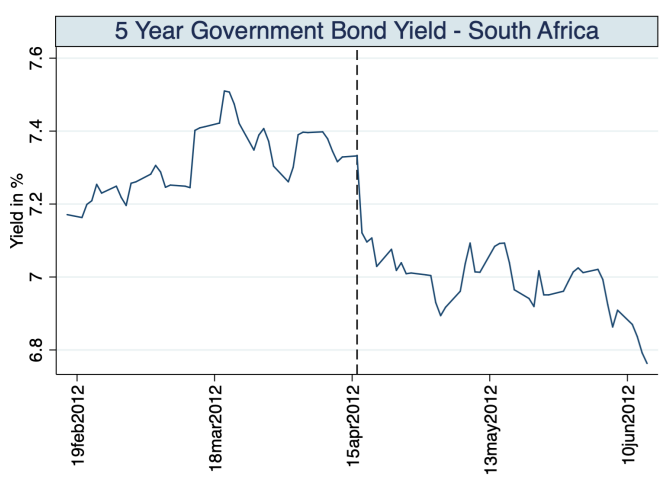

South Africa

Note: This figure displays the time series evolution of the 5-year domestic government bond yield for Colombia, Czech Republic, Mexico, Nigeria, Romania and South Africa. Yields are in percentage and are displayed in a window of +-60 trading days. The dashed line indicates the announcement date for each country. Data for the yields are obtained from Bloomberg. 
Figure 5: Time Series Exchange Rate
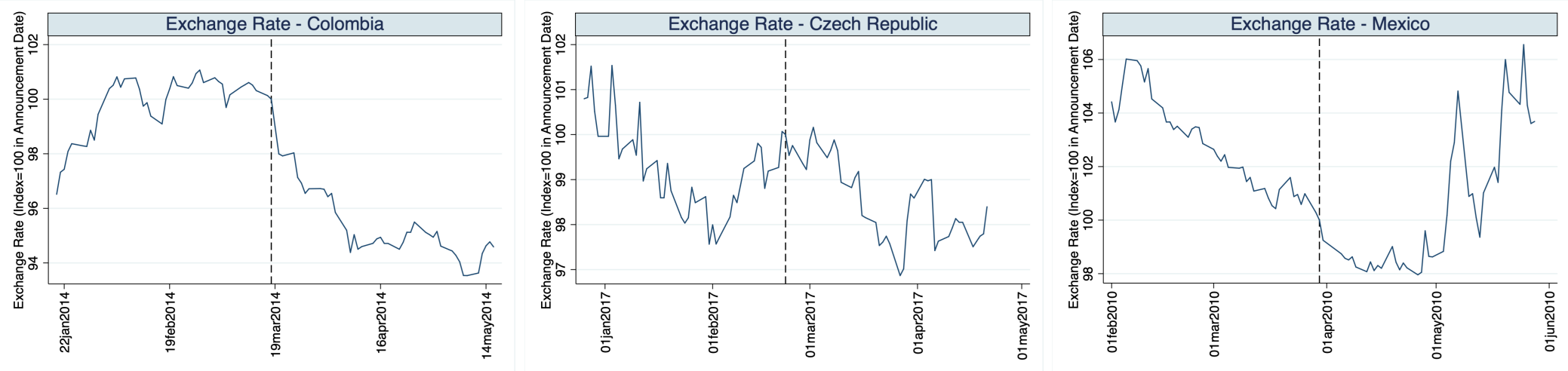

Colombia

Czech Republic

Mexico

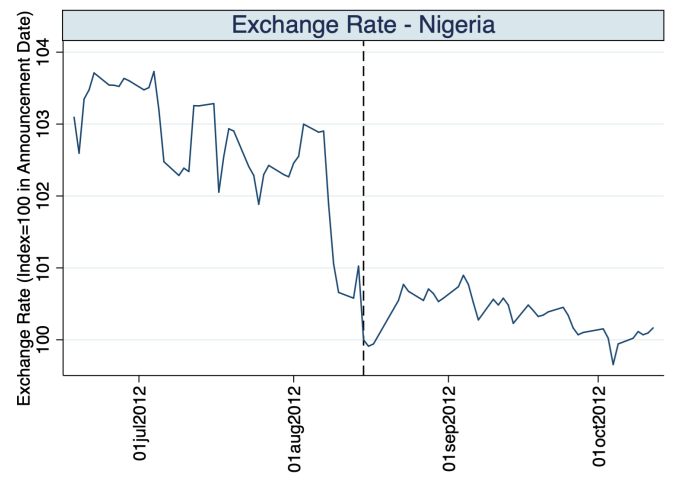

Nigeria

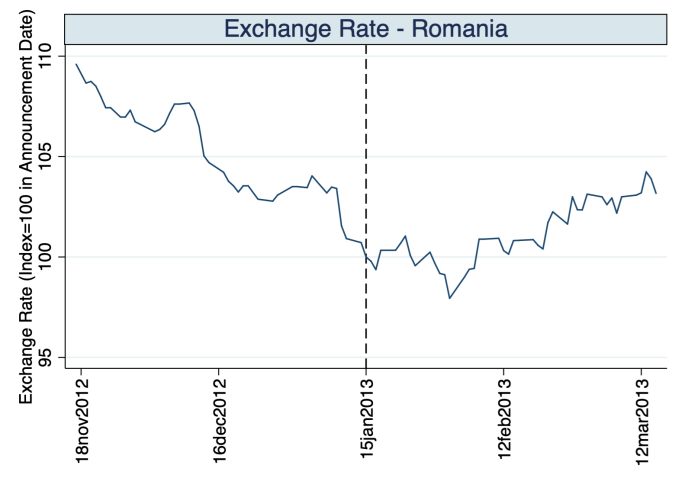

Romania

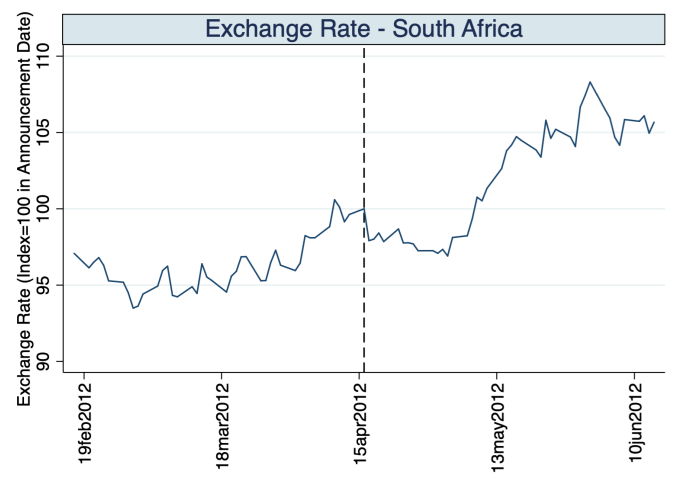

South Africa

Note: This figure displays the time series evolution of the exchange rate for Colombia, Czech Republic, Mexico, Nigeria, Romania and South Africa. Exchange rates are in local currency per unit of US dollars and are displayed in a window of +-60 trading days. The blue line is an index of this exchange rate that is equal to 100 in the announcement date. The dashed line indicates the announcement date for each country. Data for the exchange rates are obtained from Datastream. 
Figure 6: Histogram 2-day Change 5Y Government Bond Yield

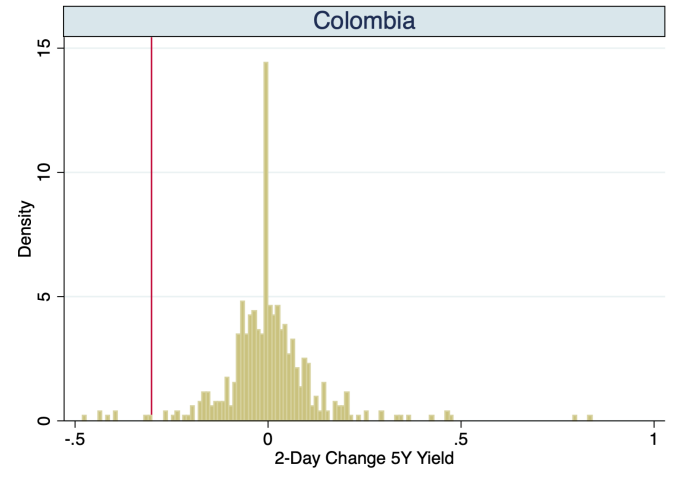

Colombia

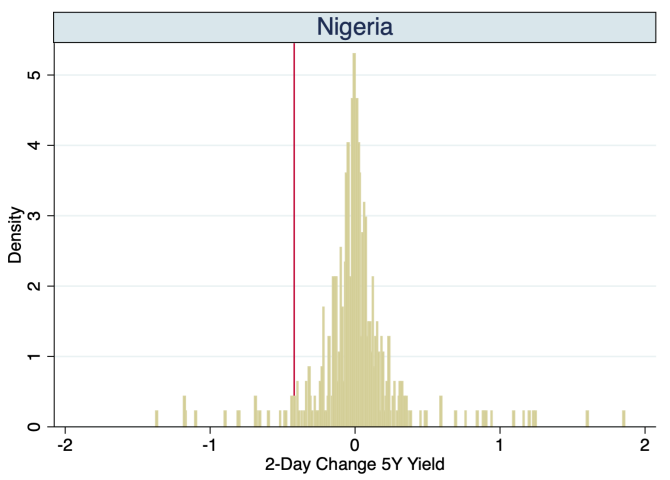

Nigeria

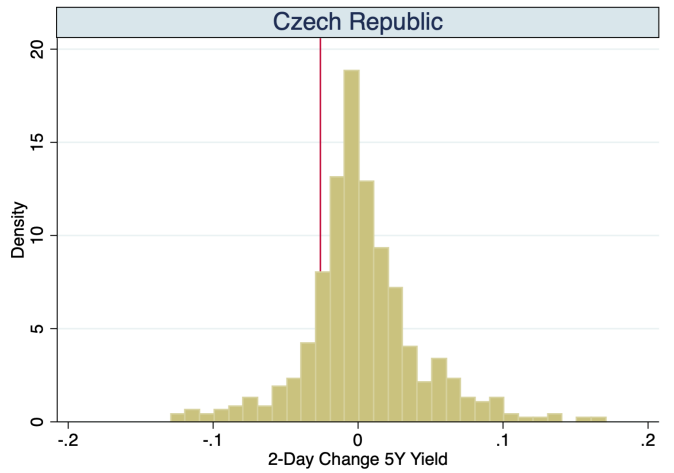

Czech Republic

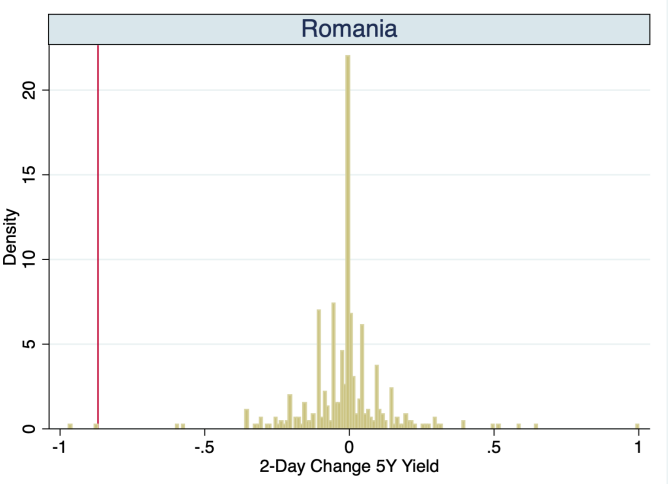

Romania

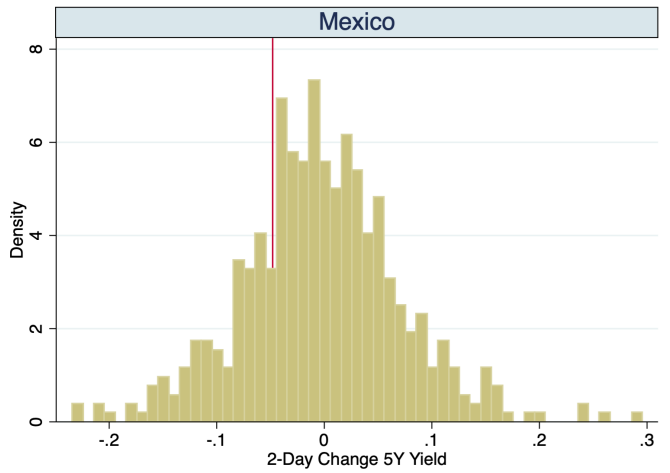

Mexico

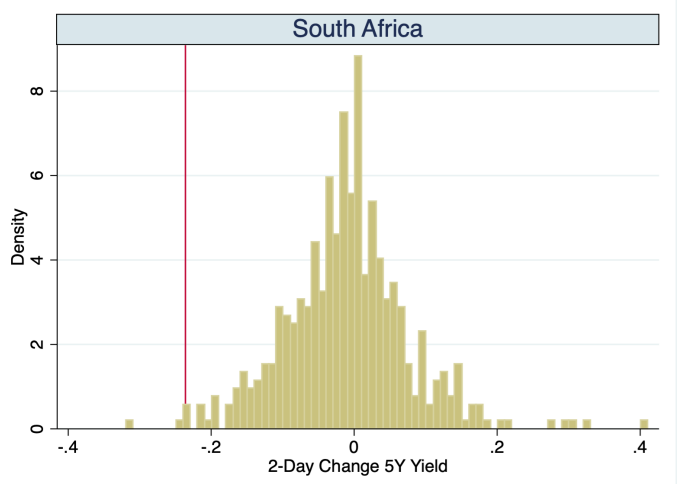

South Africa

Note: This figure displays the histogram of 2-day changes in the 5-year domestic government bond yield for Colombia, Czech Republic, Mexico, Nigeria, Romania and South Africa. The sample is composed of the +-360 trading days around the announcement dates. The red line indicates the value of the change in the yield 2 days after the announcement date. Data for the yields are obtained from Bloomberg. 
Figure 7: Histogram 2-day Change Log Exchange Rate

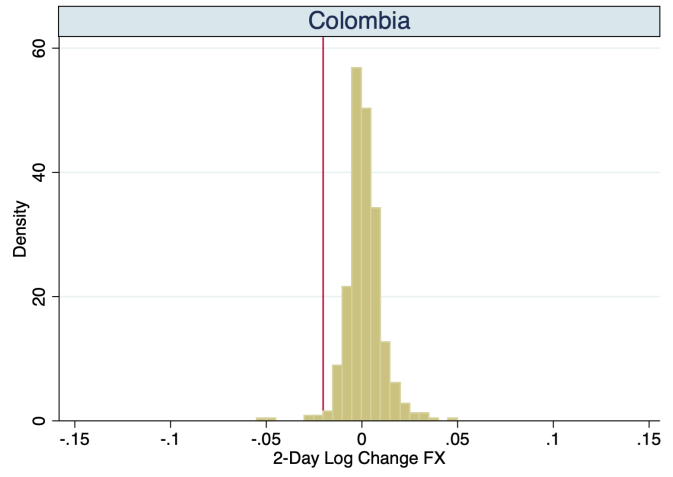

Colombia

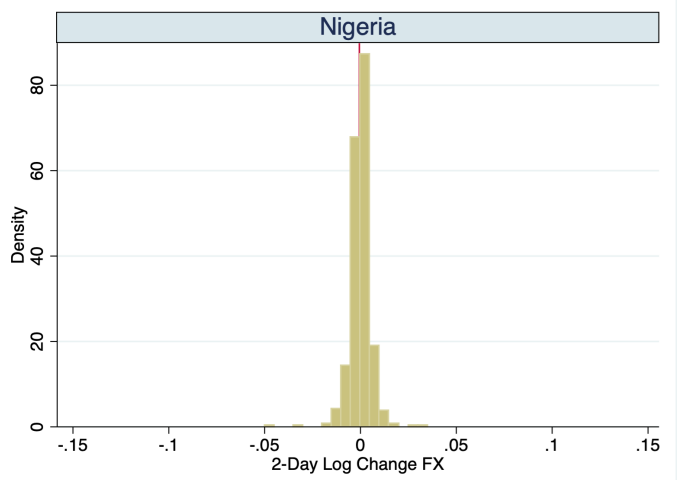

Nigeria

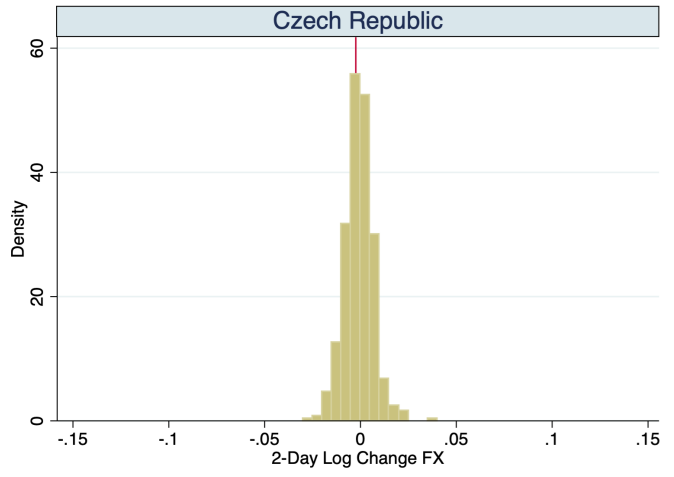

Czech Republic

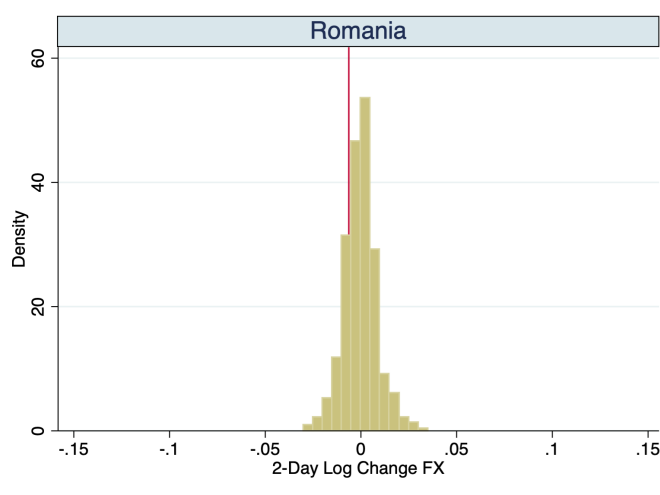

Romania

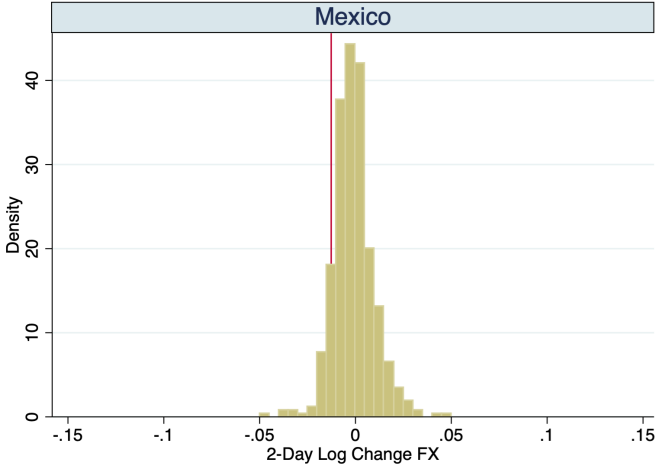

Mexico

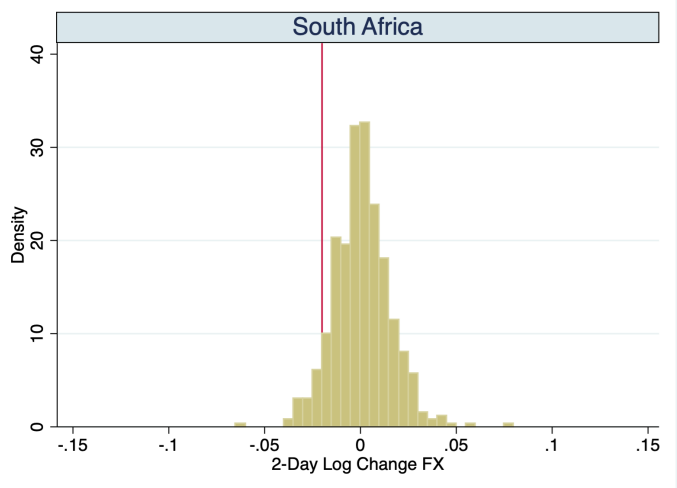

South Africa

Note: This figure displays the histogram of 2-day changes in the log of the exchange rate for Colombia, Czech Republic, Mexico, Nigeria, Romania and South Africa. Exchange rates are in local currency per unit of US dollars. The sample is composed of the +-360 trading days around the announcement dates. The red line indicates the value of the change in the log exchange rate 2 days after the announcement date. Data for the exchange rate are obtained from Datastream. 
Figure 8: Cumulative Abnormals Returns and Shocks

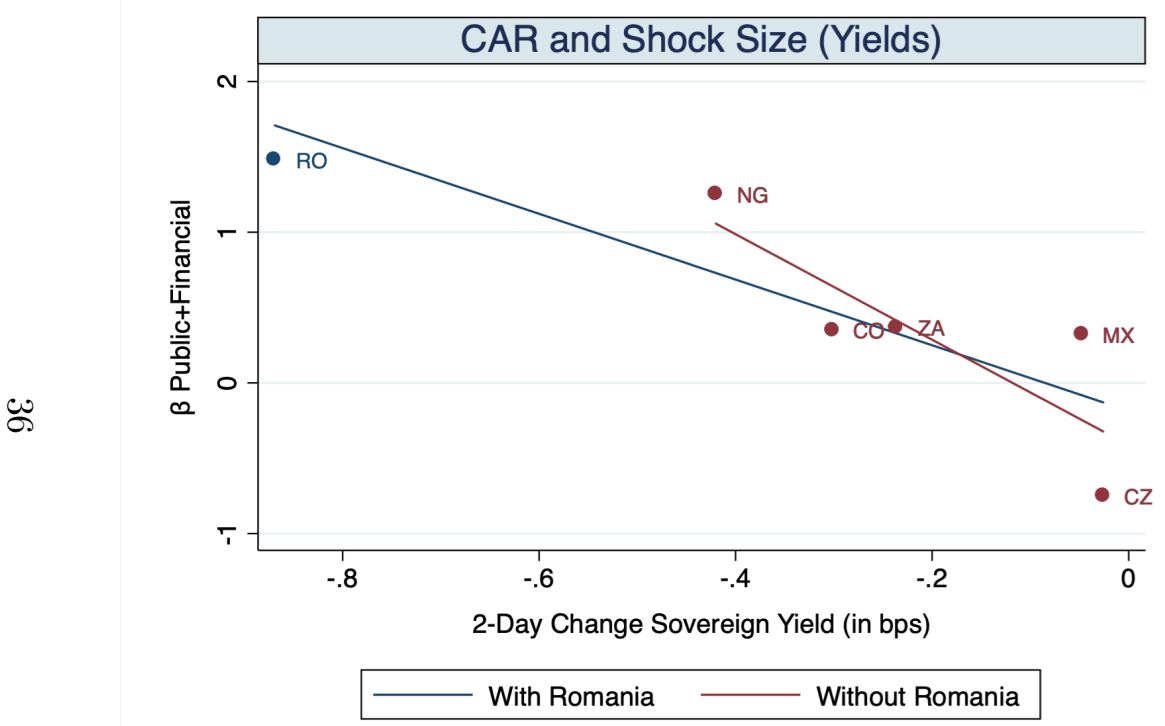

Sovereign Yield Shock

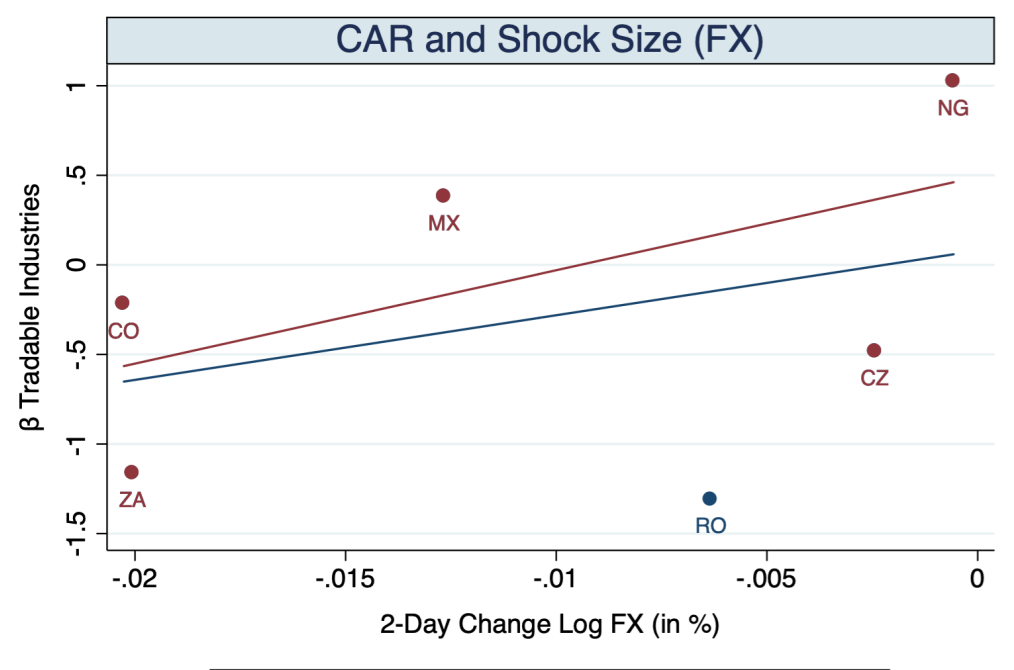

With Romania

Exchange Rate Shock

Note: This figure shows the relationship between the size of the shock for yields and the exchange rate, and the heterogeneous effects on firms. $\beta_{\mathrm{Public}}+\mathrm{Financial}$ and $\beta_{\text {Tradable Industries }}$ are obtained from a regression of $C A R_{i}^{3-\text { factor }}=\beta_{\text {Tradable Industries }} \mathbb{1}_{\text {Tradable }}+\beta_{\text {Public }+ \text { Financial }} \mathbb{1}_{\text {Public }+ \text { Financial }}+\beta_{3} E F D_{i}+\varepsilon_{i}$ for each country. The 2-day Change Sovereign Yield (Log FX) is the change 2 days after the announcement date for each country of the respective variable. 
Figure 9: Balance of Payments: Private versus Sovereign Inflows

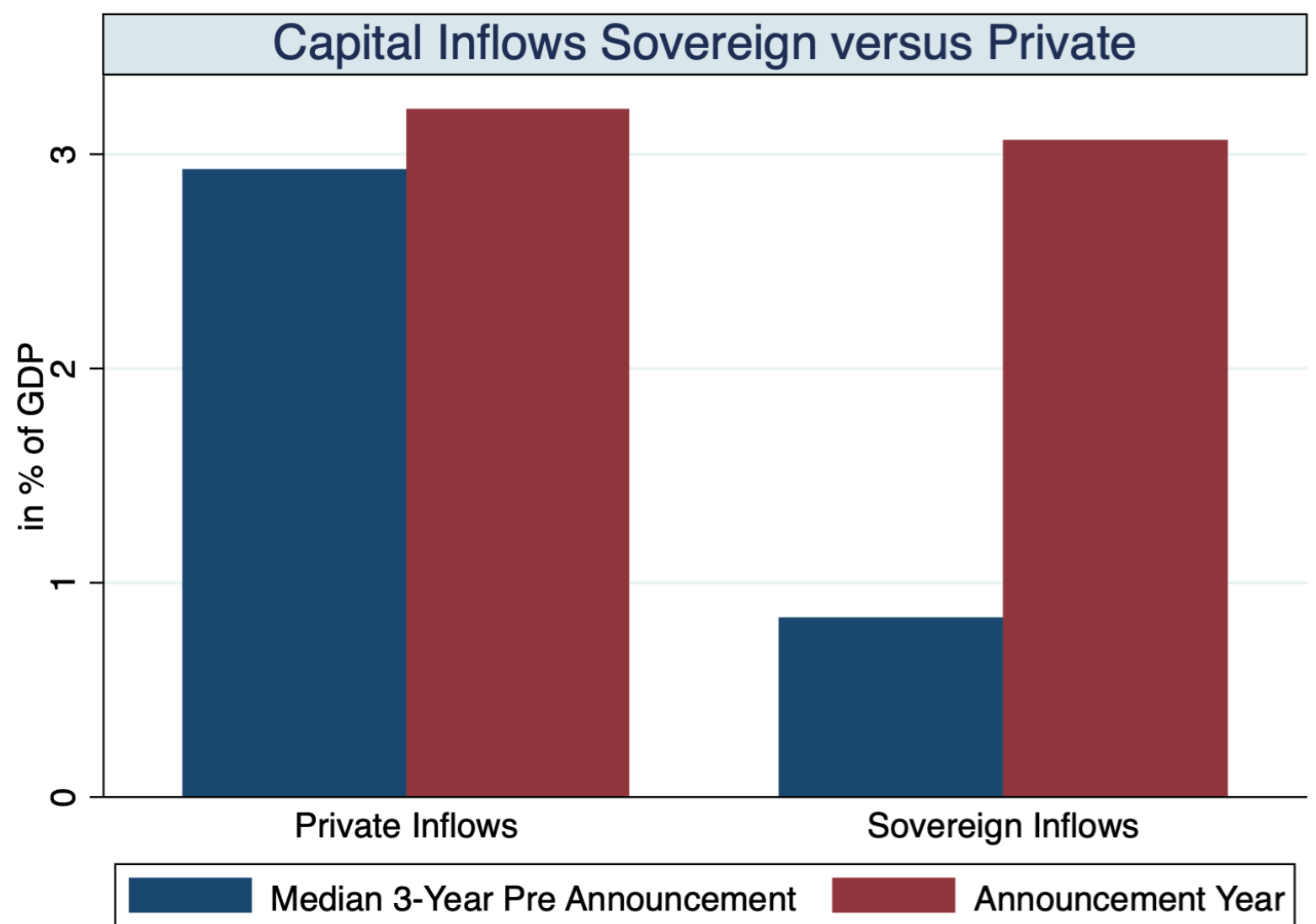

Note: This figure shows statistics for the balance of payments of Colombia, Czech Republic, Mexico, Nigeria, Romania and South Africa. Private inflows are the sum of the foreign direct investment, portfolio equity and private debt inflows. Sovereign inflows are public debt inflows. Both measures are in U.S. dollars and are normalized by the GDP in U.S. dollars. The blue bars are the median for both measures in the 3 years previous to the year of the announcement. The red bar indicates the year of the announcement. Then, we compute the median across countries. The data is from the IMF Balance of Payments Statistics and IMF WEO. 
Figure 10: Local and Foreign Currency Yields

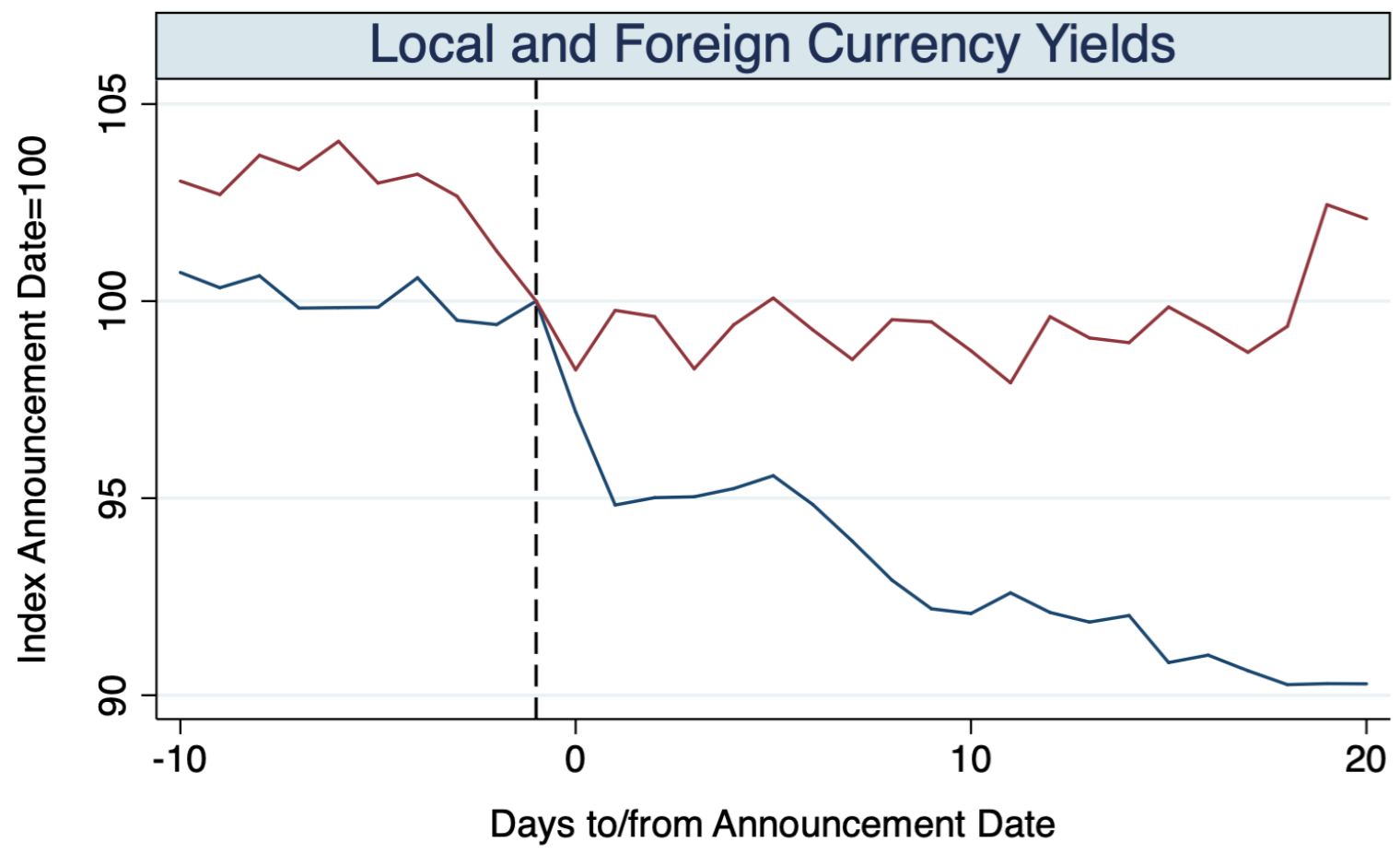

Local Currency 5-Year Government Bond Yield Foreign Currency Stripped Spread

Note: This figure shows the time evolution of the 5-year local currency government bond yields (in blue) and J.P. Morgan EMBI foreign currency sovereign spreads (in red) for Colombia, Mexico, Nigeria, Romania and South Africa around the announcement date. Both lines are computed as an index $=100$ for the announcement date. The index is computed by taking the log change in both variables for every country and then computing the average across countries to construct the index. Data is from Bloomberg and Thomson Reuters Datastream. 
Figure 11: FIR and Shocks

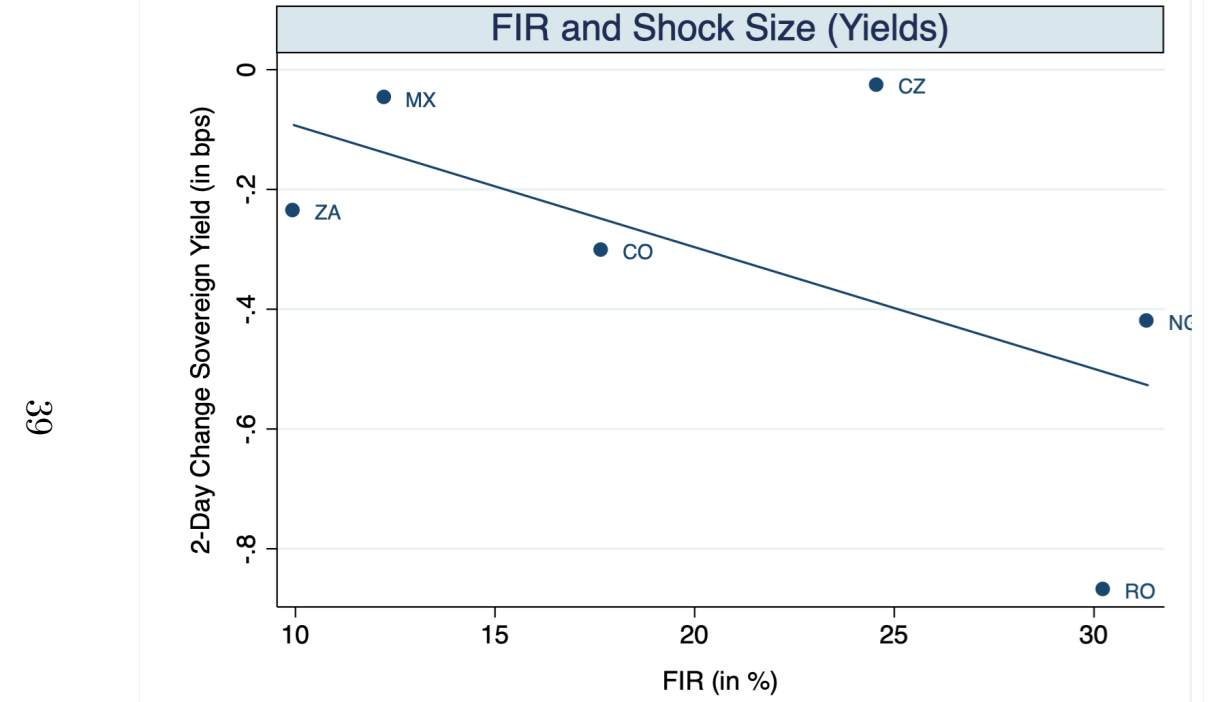

Sovereign Yield Shock

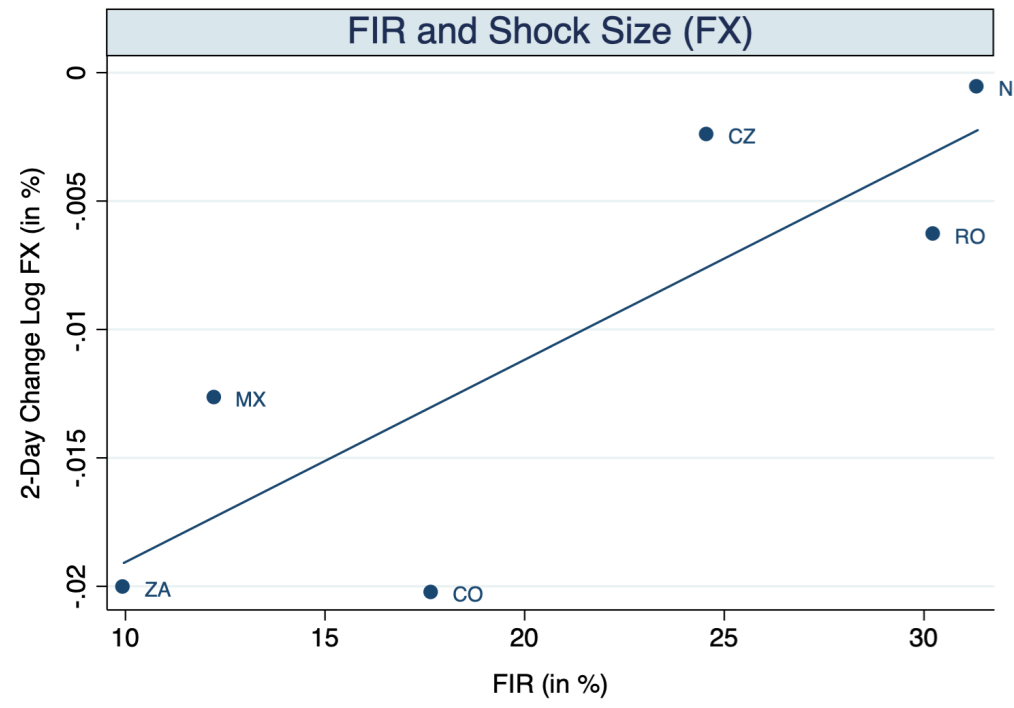

Exchange Rate Shock

Note: This figure shows the relationship between the size of the shock for yields and the exchange rate, and the estimated Flows Implied by the Rebalancing (FIR) for each country. FIR is computed as the change in benchmark weight, calculated over the entire implementation period, multiplied by the assets under management of funds tracking their returns against the corresponding benchmark index, normalized total market value of each country's sovereign debt market prior to the announcement. The 2-day Change Sovereign Yield (Log FX) is the change 2 days after the announcement date for each country of the respective variable. 
Table 1: Shocks to Government Bond Yields and Exchange Rate

This table displays the shocks to the government bond yields and exchange rates relative to the sample means. Shock $\Delta Y$ ield $(\Delta \log (F X))$ is the change in the 5-year domestic government bond yield (log exchange rate) 2 days after the announcement date in basis points. Mean $\Delta$ Y ield $(\Delta \log (F X))$ is the sample mean (in parenthesis the standard error) of a sample of +-360 trading days. Difference is a test of differences between Shock $\Delta$ Y ield $(\Delta \log (F X))$ and Mean $\Delta Y$ ield $(\Delta \log (F X))$. *, **, ***, denotes significance levels at the 10,5 , and 1 percent level, respectively.

\begin{tabular}{lcccccc}
\hline \hline Country & Shock $\Delta$ Yield & Mean $\Delta$ Yield & Difference & Shock $\Delta \log (F X)$ & Mean $\Delta \log (F X)$ & Difference \\
\hline Colombia & -30.2 & $0.40(0.53)$ & $-30.6^{* * *}$ & -2.03 & $0.15(0.04)$ & $-2.18^{* * *}$ \\
Czech Republic & -2.6 & $0.32(0.18)$ & $-2.9^{* * *}$ & -0.24 & $-0.05(0.03)$ & $-0.19^{* * *}$ \\
Mexico & -4.8 & $-0.25(0.33)$ & $-4.55^{* * *}$ & -1.27 & $-0.07(0.05)$ & $-1.20^{* * *}$ \\
Nigeria & -52.0 & $0.78(1.36)$ & $-52.8^{* * *}$ & 0.63 & $0.02(0.03)$ & $0.61^{* * *}$ \\
Romania & -86.9 & $-1.02(0.69)$ & $-85.9^{* * *}$ & -0.63 & $0.03(0.04)$ & $-0.66^{* * *}$ \\
South Africa & -23.6 & $-0.99(0.38)$ & $-22.6^{* * *}$ & -2.01 & $0.11(0.06)$ & $-2.11^{* * *}$ \\
\hline \hline
\end{tabular}


Table 2: Aggregate Stock Returns

Note: This table presents OLS estimations of cumulative abnormal returns (CAR) against a constant term. Panel A shows the CAR accumulated for 2 days after the announcement date. Panel B displays the CAR accumulated for 2 days starting 3 days before the announcement date. The detrended returns are excess returns minus their average in the previous year. The 1-factor model contains a regional factor (the MSCI EM Index). The 2-factor model contains includes, on top of the regional factor (the MSCI EM Index), a global factor (the MSCI World Index). The 5-factor models adds the small minus big (SMB), high minus low (HML), and momentum (WML) factors. The estimation only includes firms that trade in the domestic market. We discard CAR that are outside the 1th and 99 th percentile of the distribution for each country. Standard errors are in parenthesis and are clustered at the industry level. *, **, ***, denotes significance levels at the 10,5 , and 1 percent level, respectively.

\begin{tabular}{|c|c|c|c|c|}
\hline \multicolumn{5}{|c|}{ Panel A: 2-Day Cumulative Abnormal Returns (Announcement Date) } \\
\hline & Detrended Returns & 1-Factor Model & 2-Factor Model & 5-Factor Model \\
\hline \multirow[t]{2}{*}{ Constant } & 0.184 & 0.172 & 0.132 & 0.184 \\
\hline & $(0.113)$ & $(0.120)$ & $(0.121)$ & $(0.114)$ \\
\hline N. of Countries & 6 & 6 & 6 & 6 \\
\hline Observations & 855 & 855 & 855 & 855 \\
\hline $\mathrm{R}^{2}$ & 0.00 & 0.00 & 0.00 & 0.00 \\
\hline \multicolumn{5}{|c|}{ Panel B: 2-Day Cumulative Abnormal Returns (3 days before Announcement Date) } \\
\hline & Detrended Returns & 1-Factor Model & 2-Factor Model & 5-Factor Model \\
\hline \multirow[t]{2}{*}{ Constant } & 0.114 & -0.002 & 0.033 & -0.008 \\
\hline & $(0.094)$ & $(0.091)$ & $(0.090)$ & $(0.107)$ \\
\hline N. of Countries & 6 & 6 & 6 & 6 \\
\hline Observations & 855 & 855 & 855 & 855 \\
\hline $\mathrm{R}^{2}$ & 0.00 & 0.00 & 0.00 & 0.00 \\
\hline
\end{tabular}


Table 3: Firm Heterogeneity

Note: This table presents OLS estimations of cumulative abnormal returns (CAR) against different explanatory variables. Panel A shows the CAR accumulated for 2 days after the announcement date. Panel B displays the CAR accumulated for 2 days starting 3 days before the announcement date. Govt+Financial is an indicator variable that is 1 for government related and financial firms. Tradable is an indicator variable for firms in tradable industries following the Mian and Sufi (2014) classification. The detrended returns are excess returns minus their average in the previous year. The 1-factor model contains a regional factor (the MSCI EM Index). The 2-factor model contains includes, on top of the regional factor (the MSCI EM Index), a global factor (the MSCI World Index). The 5-factor models adds the small minus big (SMB), high minus low (HML), and momentum (WML) factors. The estimation only includes firms that trade in the domestic market. We discard CAR that are outside the 1 th and 99 th percentile of the distribution for each country. Standard errors are in parenthesis and are clustered at the industry level. *, **, ***, denotes significance levels at the 10,5 , and 1 percent level, respectively.

\begin{tabular}{|c|c|c|c|c|}
\hline \multicolumn{5}{|c|}{ Panel A: 2-Day Cumulative Abnormal Returns (Announcement Date) } \\
\hline & Detrended Returns & 1-Factor Model & 2-Factor Model & 5-Factor Model \\
\hline \multirow{2}{*}{ Govt+Financial } & $0.552^{* * *}$ & $0.593^{* * *}$ & $0.595 * * *$ & $0.515^{* *}$ \\
\hline & $(0.189)$ & $(0.196)$ & $(0.200)$ & $(0.202)$ \\
\hline \multirow[t]{2}{*}{ Tradable } & -0.374 & -0.331 & -0.410 & -0.271 \\
\hline & $(0.243)$ & $(0.255)$ & $(0.252)$ & $(0.245)$ \\
\hline N. of Countries & 6 & 6 & 6 & 6 \\
\hline Observations & 855 & 855 & 855 & 855 \\
\hline $\mathrm{R}^{2}$ & 0.02 & 0.02 & 0.02 & 0.01 \\
\hline \multicolumn{5}{|c|}{ Panel B: 2-Day Cumulative Abnormal Returns (3 days before Announcement Date) } \\
\hline & Detrended Returns & 1-Factor Model & 2-Factor Model & 5-Factor Model \\
\hline \multirow[t]{2}{*}{ Govt+Financial } & 0.110 & 0.056 & 0.055 & 0.245 \\
\hline & $(0.187)$ & $(0.202)$ & $(0.204)$ & $(0.188)$ \\
\hline \multirow[t]{2}{*}{ Tradable } & 0.251 & 0.191 & 0.197 & 0.174 \\
\hline & $(0.221)$ & $(0.203)$ & $(0.202)$ & $(0.244)$ \\
\hline N. of Countries & 6 & 6 & 6 & 6 \\
\hline Observations & 855 & 855 & 855 & 855 \\
\hline $\mathrm{R}^{2}$ & 0.00 & 0.00 & 0.00 & 0.00 \\
\hline
\end{tabular}




\section{Table 4: Firm Heterogeneity and External Financial Dependence}

Note: This table presents OLS estimations of cumulative abnormal returns (CAR) against different explanatory variables. Panel A shows the CAR accumulated for 2 days after the announcement date. Panel B displays the CAR accumulated for 2 days starting 3 days before the announcement date. Govt+Financial is an indicator variable that is 1 for government related and financial firms. Tradable is an indicator variable for firms in tradable industries following the Mian and Sufi (2014) classification. External FD is a proxy of the financial external dependence. We compute it following Rajan and Zingales (1998) as capital expenditures minus cash flows from operations over capital expenditures, using balance sheet data relative to the year preceding the shock. The detrended returns are excess returns minus their average in the previous year. The 1-factor model contains a regional factor (the MSCI EM Index). The 2 -factor model contains includes, on top of the regional factor (the MSCI EM Index), a global factor (the MSCI World Index). The 5 -factor models adds the small minus big (SMB), high minus low (HML), and momentum (WML) factors. The estimation only includes firms that trade in the domestic market. We discard CAR that are outside the 1th and 99th percentile of the distribution for each country. Standard errors are in parenthesis and are clustered at the industry level. *, **, ***, denotes significance levels at the 10,5 , and 1 percent level, respectively.

\begin{tabular}{|c|c|c|c|c|}
\hline \multicolumn{5}{|c|}{ Panel A: 2-Day Cumulative Abnormal Returns (Announcement Date) } \\
\hline & Detrended Returns & 1-Factor Model & 2-Factor Model & 5-Factor Model \\
\hline \multirow[t]{2}{*}{ Govt+Financial } & $0.465^{* *}$ & $0.507 * *$ & $0.508^{* *}$ & $0.473^{* *}$ \\
\hline & $(0.195)$ & $(0.201)$ & $(0.207)$ & $(0.223)$ \\
\hline \multirow[t]{2}{*}{ Tradable } & $-0.569^{* *}$ & $-0.518^{*}$ & $-0.634^{* *}$ & -0.434 \\
\hline & $(0.280)$ & $(0.299)$ & $(0.294)$ & $(0.311)$ \\
\hline \multirow[t]{2}{*}{ External FD } & $0.001^{* * *}$ & $0.001^{* * *}$ & $0.001^{* * *}$ & $0.001^{* *}$ \\
\hline & $(0.000)$ & $(0.000)$ & $(0.000)$ & $(0.000)$ \\
\hline N. of Countries & 6 & 6 & 6 & 6 \\
\hline Observations & 569 & 570 & 570 & 573 \\
\hline $\mathrm{R}^{2}$ & 0.02 & 0.02 & 0.03 & 0.02 \\
\hline \multicolumn{5}{|c|}{ Panel B: 2-Day Cumulative Abnormal Returns (3 days before Announcement Date) } \\
\hline & Detrended Returns & 1-Factor Model & 2-Factor Model & 5-Factor Model \\
\hline \multirow{2}{*}{ Govt+Financial } & 0.063 & -0.017 & -0.024 & 0.120 \\
\hline & $(0.235)$ & $(0.250)$ & $(0.253)$ & $(0.232)$ \\
\hline \multirow[t]{2}{*}{ Tradable } & 0.288 & 0.230 & 0.246 & 0.243 \\
\hline & $(0.295)$ & $(0.279)$ & $(0.274)$ & $(0.267)$ \\
\hline \multirow[t]{2}{*}{ External FD } & 0.001 & 0.001 & 0.001 & 0.001 \\
\hline & $(0.001)$ & $(0.001)$ & $(0.001)$ & $(0.001)$ \\
\hline N. of Countries & 6 & 6 & 6 & 6 \\
\hline Observations & 573 & 573 & 573 & 573 \\
\hline $\mathrm{R}^{2}$ & 0.01 & 0.00 & 0.01 & 0.00 \\
\hline
\end{tabular}


Table 5: Firm Heterogeneity and External Financial Dependence with Country Fixed Effects

Note: This table presents OLS estimations of cumulative abnormal returns (CAR) against different explanatory variables with country fixed effects. Panel A shows the CAR accumulated for 2 days after the announcement date. Panel B displays the CAR accumulated for 2 days starting 3 days before the announcement date. Govt+Financial is an indicator variable that is 1 for government related and financial firms. Tradable is an indicator variable for firms in tradable industries following the Mian and Sufi (2014) classification. External FD is a proxy of the financial external dependence. We compute it following Rajan and Zingales (1998) as capital expenditures minus cash flows from operations over capital expenditures, using balance sheet data relative to the year preceding the shock. The detrended returns are excess returns minus their average in the previous year. The detrended returns are excess returns minus their average in the previous year. The 1 -factor model contains a regional factor (the MSCI EM Index). The 2-factor model contains includes, on top of the regional factor (the MSCI EM Index), a global factor (the MSCI World Index). The 5-factor models adds the small minus big (SMB), high minus low (HML), and momentum (WML) factors. The estimation only includes firms that trade in the domestic market. We discard CAR that are outside the 1th and 99th percentile of the distribution for each country. Standard errors are in parenthesis and are clustered at the industry level. *, **, ***, denotes significance levels at the 10,5 , and 1 percent level, respectively. Panel A: 2-Day Cumulative Abnormal Returns (Announcement Date)

\begin{tabular}{|c|c|c|c|c|}
\hline & Detrended Returns & 1-Factor Model & 2-Factor Model & 5-Factor Model \\
\hline \multirow[t]{2}{*}{ Govt+Financial } & $0.457 * *$ & $0.492^{* *}$ & $0.473^{* *}$ & $0.439^{*}$ \\
\hline & $(0.200)$ & $(0.201)$ & $(0.203)$ & $(0.226)$ \\
\hline \multirow[t]{2}{*}{ Tradable } & $-0.520^{*}$ & -0.444 & $-0.556^{*}$ & -0.375 \\
\hline & $(0.282)$ & $(0.305)$ & $(0.296)$ & $(0.322)$ \\
\hline \multirow[t]{2}{*}{ External FD } & $0.001^{* * *}$ & $0.000 * * *$ & $0.001^{* * *}$ & $0.001^{* *}$ \\
\hline & $(0.000)$ & $(0.000)$ & $(0.000)$ & $(0.000)$ \\
\hline Country FE & Yes & Yes & Yes & Yes \\
\hline N. of Countries & 6 & 6 & 6 & 6 \\
\hline Observations & 569 & 570 & 570 & 573 \\
\hline $\mathrm{R}^{2}$ & 0.03 & 0.03 & 0.03 & 0.02 \\
\hline
\end{tabular}

Panel B: 2-Day Cumulative Abnormal Returns (3 days before Announcement Date)

\begin{tabular}{|c|c|c|c|c|}
\hline & Detrended Returns & 1-Factor Model & 2-Factor Model & 5-Factor Model \\
\hline \multirow[t]{2}{*}{ Govt+Financial } & 0.045 & -0.054 & -0.041 & 0.119 \\
\hline & $(0.251)$ & $(0.267)$ & $(0.270)$ & $(0.248)$ \\
\hline \multirow[t]{2}{*}{ Tradable } & 0.236 & 0.179 & 0.202 & 0.217 \\
\hline & $(0.275)$ & $(0.259)$ & $(0.257)$ & $(0.254)$ \\
\hline \multirow[t]{2}{*}{ External FD } & 0.001 & 0.001 & 0.001 & 0.001 \\
\hline & $(0.001)$ & $(0.001)$ & $(0.001)$ & $(0.001)$ \\
\hline Country FE & Yes & Yes & Yes & Yes \\
\hline N. of Countries & 6 & 6 & 6 & 6 \\
\hline Observations & 573 & 573 & 573 & 573 \\
\hline $\mathrm{R}^{2}$ & 0.01 & 0.01 & 0.01 & 0.01 \\
\hline
\end{tabular}


Table 6: Firm Heterogeneity with Actual Shocks

Note: This table presents OLS estimations of cumulative abnormal returns (CAR) against different explanatory variables with country fixed effects. Panel A shows the CAR accumulated for 2 days after the announcement date. Panel B displays the CAR accumulated for 2 days starting 3 days before the announcement date. (Govt+Financial) $* S^{Y \text { ield }}$ is an indicator variable that is 1 for government related and financial firms and that is interacted with the 2-day change in the yield (in basis points) for each country 2 days after the announcement date multiplied by -1 . Tradable $* S^{E R}$ is an indicator variable for firms in tradable industries following the Mian and Sufi (2014) classification that is interacted with with the 2-day change in the log exchange rate (in percentage) for each country 2 days after the announcement date multiplied by -1 . External FD $* S^{Y i e l d}$ is a proxy of the financial external dependence that is interacted with the yield 2-day change for the announcement date. We compute External FD following Rajan and Zingales (1998) as capital expenditures minus cash flows from operations over capital expenditures, using balance sheet data relative to the year preceding the shock. The detrended returns are excess returns minus their average in the previous year. The 1-factor model contains a regional factor (the MSCI EM Index). The 2-factor model contains includes, on top of the regional factor (the MSCI EM Index), a global factor (the MSCI World Index). The 5-factor models adds the small minus big (SMB), high minus low (HML), and momentum (WML) factors. The estimation only includes firms that trade in the domestic market. We discard CAR that are outside the 1 th and 99 th percentile of the distribution for each country. Standard errors are in parenthesis and are clustered at the industry level. *, **, ***, denotes significance levels at the 10,5 , and 1 percent level, respectively.

\begin{tabular}{|c|c|c|c|c|}
\hline \multicolumn{5}{|c|}{ Panel A: 2-Day Cumulative Abnormal Returns (Announcement Date) } \\
\hline & rended Returns & 1-Factor Model & 2-Factor Model & 5-Factor Model \\
\hline \multirow{2}{*}{$($ Govt + Financial $) * S^{Y i e l d}$} & $0.018^{* * *}$ & $0.019 * * *$ & $0.018^{* * *}$ & $0.014^{* *}$ \\
\hline & $(0.006)$ & $(0.006)$ & $(0.006)$ & $(0.006)$ \\
\hline \multirow[t]{2}{*}{ Tradable** $S^{E R}$} & $-0.401 * *$ & $-0.357 * *$ & $-0.417 * *$ & -0.298 \\
\hline & $(0.155)$ & $(0.171)$ & $(0.161)$ & $(0.190)$ \\
\hline \multirow[t]{2}{*}{ External $\mathrm{FD}^{*} S^{Y \text { ield }}$} & $0.001^{* * *}$ & $0.001^{* *}$ & $0.001^{* *}$ & $0.002^{* *}$ \\
\hline & $(0.000)$ & $(0.000)$ & $(0.000)$ & $(0.001)$ \\
\hline Country FE & Yes & Yes & Yes & Yes \\
\hline N. of Countries & 6 & 6 & 6 & 6 \\
\hline Observations & 569 & 570 & 570 & 573 \\
\hline $\mathrm{R}^{2}$ & 0.04 & 0.04 & 0.04 & 0.02 \\
\hline \multicolumn{5}{|c|}{ Panel B: 2-Day Cumulative Abnormal Returns (3 days before Announcement Date) } \\
\hline & Detrended Returns & 1-Factor Model & 2-Factor Model & 5-Factor Model \\
\hline \multirow[t]{2}{*}{$($ Govt + Financial $) * S^{Y i e l d}$} & 0.001 & -0.001 & -0.001 & 0.005 \\
\hline & $(0.007)$ & $(0.008)$ & $(0.008)$ & $(0.006)$ \\
\hline \multirow[t]{2}{*}{ Tradable** $S^{E R}$} & 0.129 & 0.098 & 0.113 & 0.124 \\
\hline & $(0.180)$ & $(0.173)$ & $(0.172)$ & $(0.169)$ \\
\hline \multirow[t]{2}{*}{ External $\mathrm{FD}^{*} S^{Y i e l d}$} & 0.001 & 0.001 & 0.001 & \multirow{2}{*}{$\begin{array}{c}0.001 \\
(0.001)\end{array}$} \\
\hline & $(0.001)$ & $(0.001)$ & $(0.001)$ & \\
\hline Country FE & Yes & Yes & Yes & Yes \\
\hline N. of Countries & 6 & 6 & 6 & 6 \\
\hline Observations & 573 & 573 & 573 & 573 \\
\hline $\mathrm{R}^{2}$ & 0.01 & 0.00 & 0.00 & 0.00 \\
\hline
\end{tabular}


Table 7: Aggregate Stock Returns with Actual Shocks and Other Channels

Note: This table presents OLS estimations of cumulative abnormal returns (CAR) against different explanatory variables with country fixed effects. Panel A shows the CAR accumulated for 2 days after the announcement date. Panel B displays the CAR accumulated for 2 days starting 3 days before the announcement date. (Govt+Financial) * $S^{Y i e l d}$ is an indicator variable that is 1 for government related and financial firms and that is interacted with the 2-day change in the yield (in basis points) for each country 2 days after the announcement date multiplied by -1 . Tradable $* S^{E R}$ is an indicator variable for firms in tradable industries following the Mian and Sufi (2014) classification that is interacted with with the 2-day change in the log exchange rate (in percentage) for each country 2 days after the announcement date multiplied by -1 . External FD $* S^{\text {Yield }}$ is a proxy of the financial external dependence that is interacted with the yield 2-day change for the announcement date. We compute External FD following Rajan and Zingales (1998) as capital expenditures minus cash flows from operations over capital expenditures, using balance sheet data relative to the year preceding the shock. Corporate Debt is an indicator variable that is 1 if a firm has issued corporate debt in the past five years before the announcement year and 0 otherwise. Foreign Ownership is an indicator variable that is 1 if the firm is in the MSCI Emerging Markets Index in the year previous to the announcement date and 0 otherwise. The detrended returns are excess returns minus their average in the previous year. The 1-factor model contains a regional factor (the MSCI EM Index). The 2-factor model contains includes, on top of the regional factor (the MSCI EM Index), a global factor (the MSCI World Index). The 5-factor models adds the small minus big (SMB), high minus low (HML), and momentum (WML) factors. The estimation only includes firms that trade in the domestic market. We discard CAR that are outside the 1th and 99th percentile of the distribution for each country. Standard errors are in parenthesis and are clustered at the industry level. $*, * *, * * *$, denotes significance levels at the 10,5 , and 1 percent level, respectively.

\begin{tabular}{|c|c|c|c|c|c|c|c|c|}
\hline \multicolumn{9}{|c|}{ Panel A: 2-Day Cumulative Abnormal Returns (Announcement Date) } \\
\hline & \multicolumn{2}{|c|}{ Detrended Returns } & \multicolumn{2}{|c|}{ 1-Factor Model } & \multicolumn{2}{|c|}{ 2-Factor Model } & \multicolumn{2}{|c|}{ 5-Factor Model } \\
\hline \multicolumn{2}{|c|}{$($ Govt + Financial $) * S^{Y i}{ }^{2} Q_{l} Q^{13} 3^{* *}$} & $0.013^{* *}$ & $0.014^{* *}$ & $0.014^{* *}$ & $0.014^{* *}$ & $0.014^{* *}$ & $0.014^{* *}$ & $0.015^{* *}$ \\
\hline & $(0.006)$ & $(0.006)$ & $(0.006)$ & $(0.006)$ & $(0.006)$ & $(0.006)$ & $(0.006)$ & $(0.007)$ \\
\hline \multirow[t]{2}{*}{ Tradable** $S^{E R}$} & $-0.424^{* * *}$ & $-0.425 * * *$ & $-0.380 * *$ & $-0.381^{* *}$ & $-0.440 * * *$ & $-0.440^{* * *}$ & -0.295 & -0.292 \\
\hline & $(0.153)$ & $(0.153)$ & $(0.169)$ & $(0.169)$ & $(0.161)$ & $(0.160)$ & $(0.192)$ & $(0.192)$ \\
\hline \multirow[t]{2}{*}{$\begin{array}{l}\text { External } \\
\mathrm{FD}^{*} S^{Y i e l d}\end{array}$} & $0.001^{* *}$ & $0.001^{* *}$ & $0.001^{* *}$ & $0.001^{* *}$ & $0.001^{* *}$ & $0.001^{* *}$ & $0.002^{*}$ & $0.002^{* *}$ \\
\hline & $(0.000)$ & $(0.000)$ & $(0.000)$ & $(0.000)$ & $(0.001)$ & $(0.001)$ & $(0.001)$ & $(0.001)$ \\
\hline \multirow[t]{2}{*}{$\begin{array}{l}\text { Intl. Mkt. } \\
\text { Accesss* } S^{Y i e l d}\end{array}$} & 1.479 & 1.425 & 1.439 & 1.245 & 1.433 & 1.325 & -0.205 & 0.283 \\
\hline & $(1.125)$ & $(1.308)$ & $(1.091)$ & $(1.262)$ & $(1.087)$ & $(1.244)$ & $(1.056)$ & $(1.049)$ \\
\hline \multirow[t]{2}{*}{$\begin{array}{l}\text { Foreign } \\
\text { Ownership* } S^{Y \text { ield }}\end{array}$} & & 0.127 & & 0.458 & & 0.255 & & -1.149 \\
\hline & & $(0.969)$ & & $(1.001)$ & & $(1.004)$ & & (1.116) \\
\hline Country FE & Yes & Yes & Yes & Yes & Yes & Yes & Yes & Yes \\
\hline N. of Countries & 6 & 6 & 6 & 6 & 6 & 6 & 6 & 6 \\
\hline Observations & 569 & 569 & 570 & 570 & 570 & 570 & 573 & 573 \\
\hline $\mathrm{R}^{2}$ & 0.05 & 0.05 & 0.04 & 0.04 & 0.05 & 0.05 & 0.02 & 0.02 \\
\hline
\end{tabular}


Table 8: Aggregate Stock Returns with Actual Shocks and Firm Size

Note: This table presents OLS estimations of cumulative abnormal returns (CAR) against different explanatory variables with country fixed effects. Panel A shows the CAR accumulated for 2 days after the announcement date. Panel B displays the CAR accumulated for 2 days starting 3 days before the announcement date. (Govt+Financial) $* S^{Y i e l d}$ is an indicator variable that is 1 for government related and financial firms and that is interacted with the 2-day change in the yield (in basis points) for each country 2 days after the announcement date multiplied by -1 . Tradable $* S^{E R}$ is an indicator variable for firms in tradable industries following the Mian and Sufi (2014) classification that is interacted with with the 2-day change in the log exchange rate (in percentage) for each country 2 days after the announcement date multiplied by -1 . External FD $* S^{Y i e l d}$ is a proxy of the financial external dependence that is interacted with the yield 2-day change for the announcement date. We compute External FD following Rajan and Zingales (1998) as capital expenditures minus cash flows from operations over capital expenditures, using balance sheet data relative to the year preceding the shock. Corporate Debt is an indicator variable that is 1 if a firm has issued corporate debt in the past five years before the announcement year and 0 otherwise. Foreign Ownership is an indicator variable that is 1 if the firm is in the MSCI Emerging Markets Index in the year previous to the announcement date and 0 otherwise. Log Assets is the lagged log of total assets. The detrended returns are excess returns minus their average in the previous year. The 1 -factor model contains a regional factor (the MSCI EM Index). The 2-factor model contains includes, on top of the regional factor (the MSCI EM Index), a global factor (the MSCI World Index). The 5-factor models adds the small minus big (SMB), high minus low (HML), and momentum (WML) factors. The estimation only includes firms that trade in the domestic market. We discard CAR that are outside the 1th and 99th percentile of the distribution for each country. Standard errors are in parenthesis and are clustered at the industry level. *, **, ***, denotes significance levels at the 10,5 , and 1 percent level, respectively.

\begin{tabular}{|c|c|c|c|c|}
\hline \multicolumn{5}{|c|}{ Panel A: 2-Day Cumulative Abnormal Returns (Announcement Date) } \\
\hline & trended Returns & 1-Factor Model & 2-Factor Model & 5-Factor Model \\
\hline \multirow[t]{2}{*}{$($ Govt + Financial $) * S^{Y i e l d}$} & $0.014^{* *}$ & $0.014^{* *}$ & $0.014^{* *}$ & $0.019^{* * *}$ \\
\hline & $(0.006)$ & $(0.006)$ & $(0.006)$ & $(0.006)$ \\
\hline \multirow[t]{2}{*}{ Tradable $^{* *} S^{E R}$} & $-0.424^{* * *}$ & $-0.379^{* *}$ & $-0.439^{* * *}$ & -0.299 \\
\hline & $(0.153)$ & $(0.170)$ & $(0.161)$ & $(0.194)$ \\
\hline \multirow[t]{2}{*}{ External $\mathrm{FD}^{*} S^{Y i e l d}$} & $0.001^{* *}$ & $0.001^{* *}$ & $0.001^{* *}$ & $0.002^{* *}$ \\
\hline & $(0.000)$ & $(0.001)$ & $(0.001)$ & $(0.001)$ \\
\hline \multirow[t]{2}{*}{$\begin{array}{l}\text { Intl. Mkt. } \\
\text { Accesss } S^{Y \text { ield }}\end{array}$} & 1.329 & 1.150 & 1.237 & 0.499 \\
\hline & $(1.310)$ & $(1.265)$ & $(1.252)$ & $(1.053)$ \\
\hline \multirow[t]{2}{*}{$\begin{array}{l}\text { Foreign } \\
\text { Ownership } * S^{Y \text { ield }}\end{array}$} & -0.009 & 0.349 & 0.174 & -0.382 \\
\hline & $(0.949)$ & $(0.984)$ & $(1.013)$ & $(1.145)$ \\
\hline \multirow[t]{2}{*}{ Log Assets } & 0.025 & 0.022 & 0.019 & -0.100 \\
\hline & $(0.050)$ & $(0.051)$ & $(0.058)$ & $(0.079)$ \\
\hline Country FE & Yes & Yes & Yes & Yes \\
\hline N. of Countries & 6 & 6 & 6 & 6 \\
\hline Observations & 566 & 567 & 567 & 570 \\
\hline $\mathrm{R}^{2}$ & 0.05 & 0.04 & 0.05 & 0.03 \\
\hline
\end{tabular}


Table 9: Aggregate Stock Returns with Actual Shocks

Note: This table presents OLS estimations of cumulative abnormal returns (CAR) against different explanatory variables with country fixed effects. Panel A shows the CAR accumulated for 2 days after the announcement date. Panel B displays the CAR accumulated for 2 days starting 3 days before the announcement date. (Govt+Financial) * $S^{Y i e l d}$ is an indicator variable that is 1 for government related and financial firms and that is interacted with the 2-day change in the yield (in basis points) for each country 2 days after the announcement date multiplied by -1 . Tradable $* S^{E R}$ is an indicator variable for firms in tradable industries following the Mian and Sufi (2014) classification that is interacted with with the 2-day change in the log exchange rate (in percentage) for each country 2 days after the announcement date multiplied by -1 . External FD $* S^{\text {Yield }}$ is a proxy of the financial external dependence that is interacted with the yield 2-day change for the announcement date. We compute External FD following Rajan and Zingales (1998) as capital expenditures minus cash flows from operations over capital expenditures, using balance sheet data relative to the year preceding the shock. The detrended returns are excess returns minus their average in the previous year. The 1-factor model contains a regional factor (the MSCI EM Index). The 2-factor model contains includes, on top of the regional factor (the MSCI EM Index), a global factor (the MSCI World Index). The 5-factor models adds the small minus big (SMB), high minus low (HML), and momentum (WML) factors. The estimation includes firms that trade in the domestic market and stocks that trade in foreign markets but have their main operations in one of the affected countries. We discard CAR that are outside the 1th and 99th percentile of the distribution for each country. Standard errors are in parenthesis and are clustered at the industry level. *, **, ***, denotes significance levels at the 10,5 , and 1 percent level, respectively.

\begin{tabular}{|c|c|c|c|c|}
\hline \multicolumn{5}{|c|}{ Panel A: 2-Day Cumulative Abnormal Returns (Announcement Date) } \\
\hline & rended Returns & 1-Factor Model & 2-Factor Model & 5-Factor Model \\
\hline \multirow{2}{*}{$($ Govt + Financial $) * S^{\text {Yield }}$} & $0.018^{* * *}$ & $0.019 * * *$ & $0.018^{* * *}$ & $0.014^{* *}$ \\
\hline & $(0.006)$ & $(0.006)$ & $(0.006)$ & $(0.006)$ \\
\hline \multirow[t]{2}{*}{ Tradable** $S^{E R}$} & $-0.401^{* *}$ & $-0.357^{* *}$ & $-0.417^{* *}$ & -0.298 \\
\hline & $(0.155)$ & $(0.171)$ & $(0.161)$ & $(0.190)$ \\
\hline \multirow[t]{2}{*}{ External FD* $S^{Y i e l d}$} & $0.001^{* * *}$ & $0.001^{* *}$ & $0.001^{* *}$ & \multirow{2}{*}{$\begin{array}{c}0.002^{* *} \\
(0.001)\end{array}$} \\
\hline & $(0.000)$ & $(0.000)$ & $(0.000)$ & \\
\hline Country FE & Yes & Yes & Yes & Yes \\
\hline N. of Countries & 6 & 6 & 6 & 6 \\
\hline Observations & 569 & 570 & 570 & 573 \\
\hline $\mathrm{R}^{2}$ & 0.04 & 0.04 & 0.04 & 0.02 \\
\hline
\end{tabular}




\section{A Additional Tables and Figures}

Figure A.1: Coefficients for Different CAR Windows

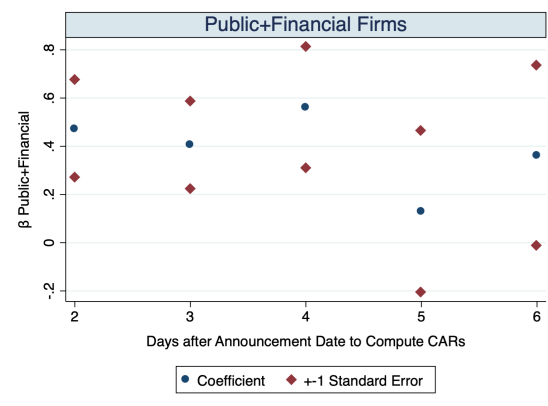

Public+Financials

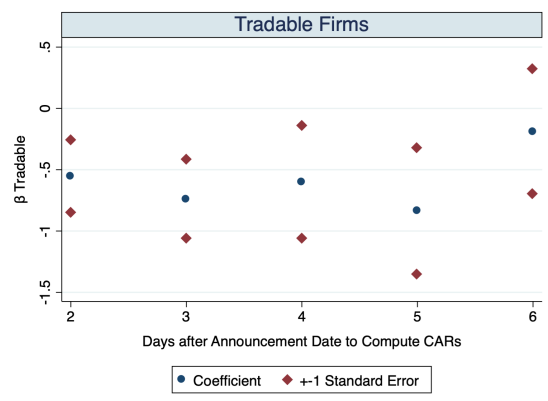

Tradable

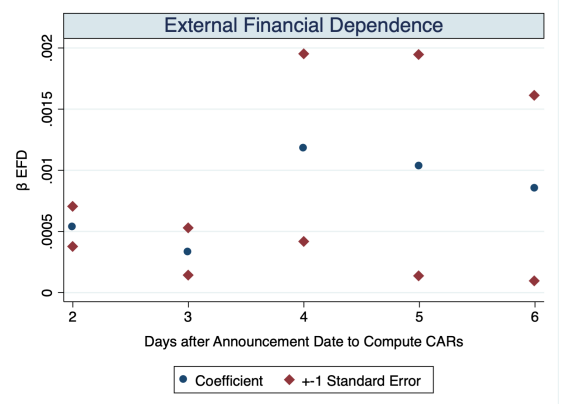

External Financial Dependence

Note: This figure shows the coefficients of OLS estimations of cumulative abnormal returns (CAR) against different explanatory variables for different windows for accumulating abnormal returns. The explanatory variables are Govt+Financial, Tradable, and External FD. Govt+Financial is an indicator variable that is 1 for government related and financial firms. Tradable is an indicator variable for firms in tradable industries following the Mian and Sufi (2014) classification. External FD is a proxy of the financial external dependence. We compute it following Rajan and Zingales (1998) as capital expenditures minus cash flows from operations over capital expenditures, using balance sheet data relative to the year preceding the shock. 
Figure A.2: Balance of Payments: Country by Country

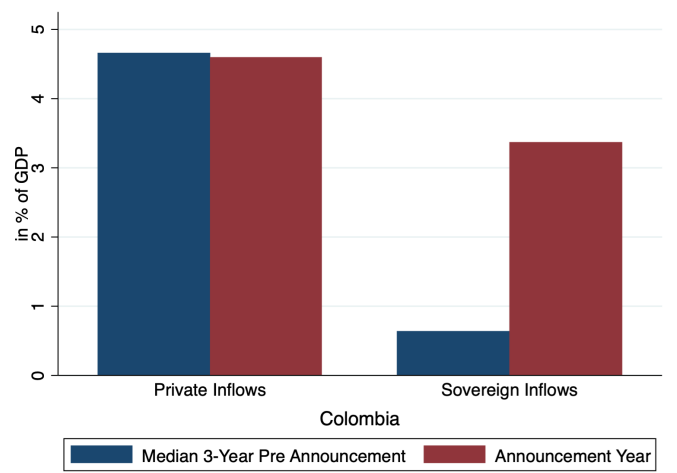

Colombia

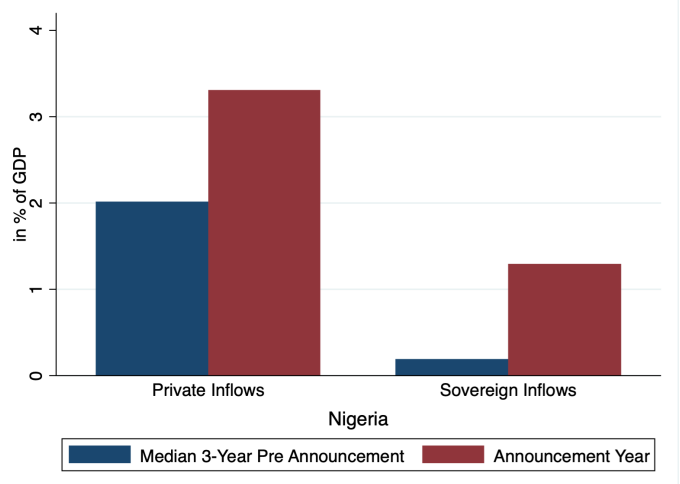

Nigeria

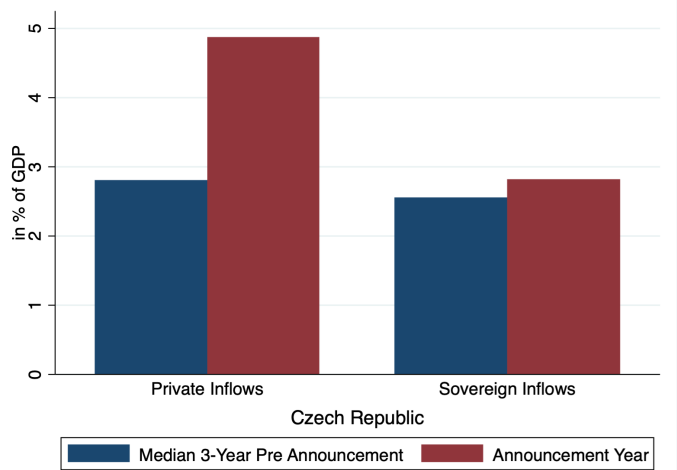

Czech Republic

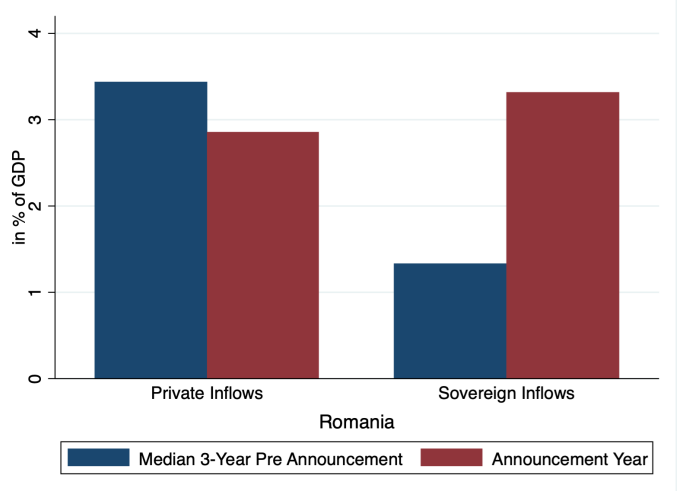

Romania

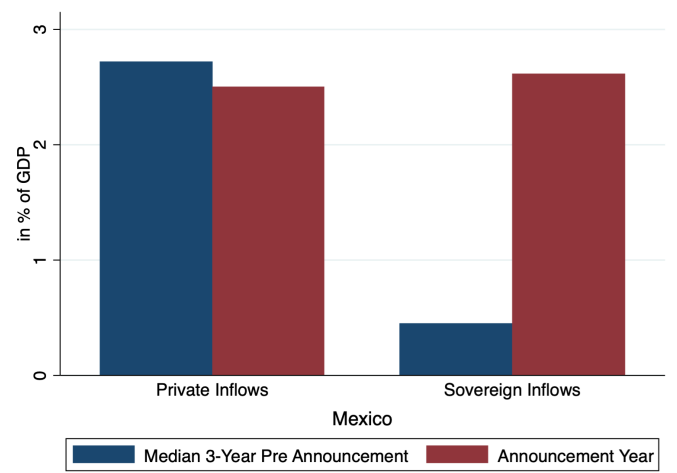

Mexico

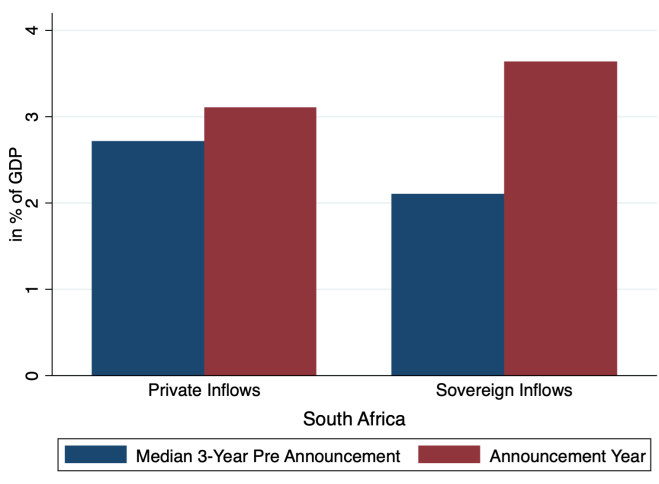

South Africa

Note: Note: This figure shows statistics for the balance of payments of Colombia, Czech Republic, Mexico, Nigeria, Romania and South Africa. Private inflows are the sum of the foreign direct investment, portfolio equity and private debt inflows. Sovereign inflows are public debt inflows. Both measures are in U.S. dollars and are normalized by the GDP in U.S. dollars. The blue bars are the median for both measures in the 3 years previous to the year of the announcement. The red bar indicates the year of the announcement. The data is from the IMF Balance of Payments Statistics and IMF WEO. 
Figure A.3: Local versus Foreign Currency Yields: Country by Country

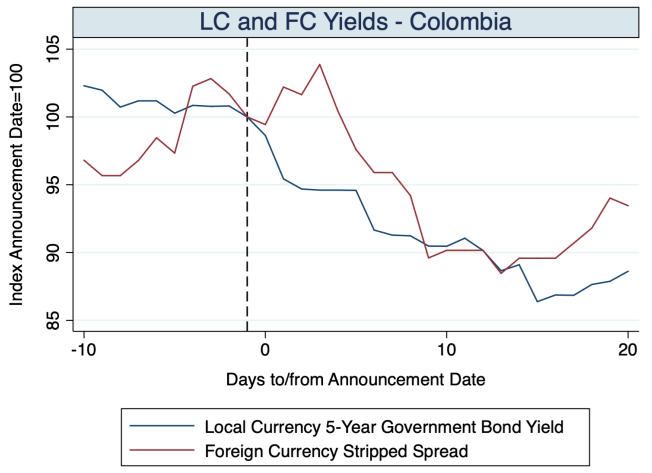

Colombia

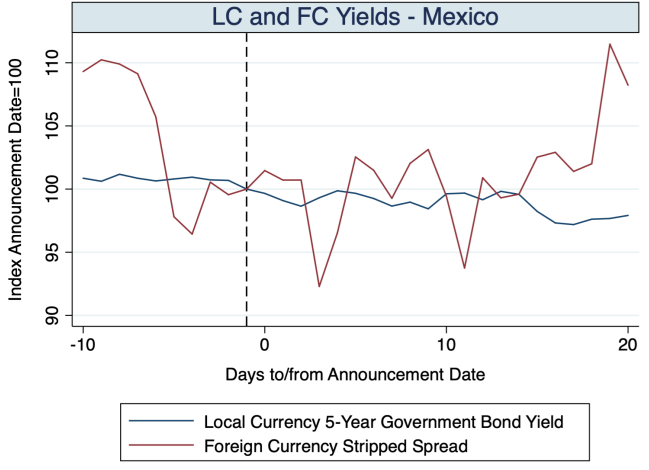

Mexico

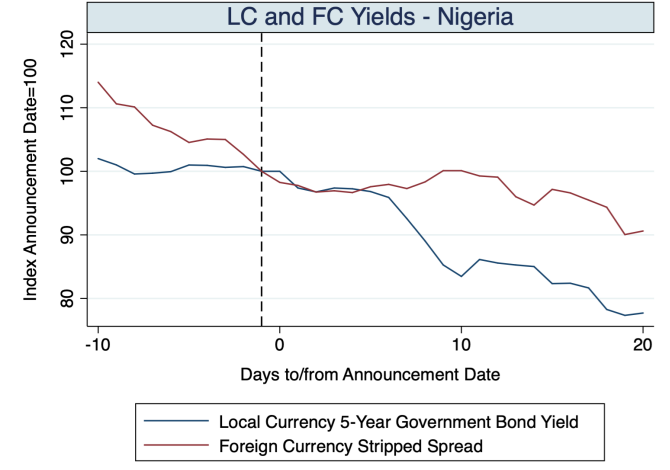

Nigeria

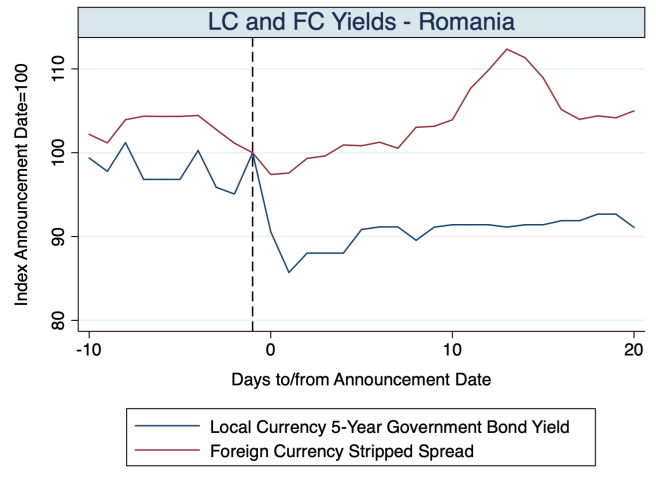

Romania

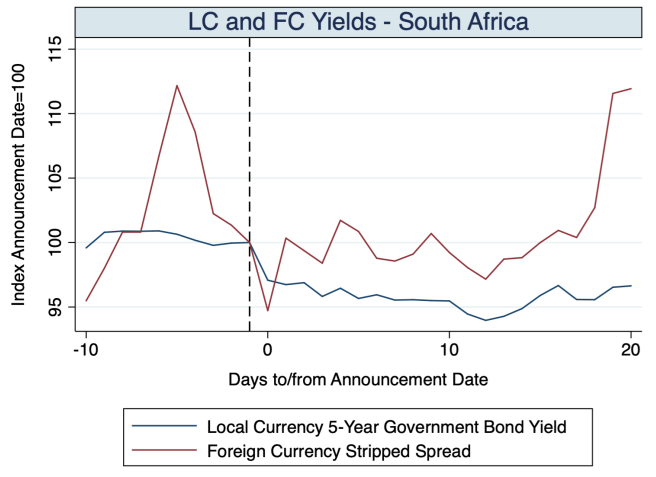

South Africa

Note: This figure shows the time evolution of the 5-year local currency government bond yields (in blue) and J.P. Morgan EMBI foreign currency sovereign spreads (in red) for Colombia, Mexico, Nigeria, Romania and South Africa around the announcement date. Both lines are computed as an index=100 for the announcement date. The index is computed by taking the log change in both variables for each country to construct the index. Data is from Bloomberg and Thomson Reuters Datastream. 
Table A.1: Estimations with Domestic Stock Market

Note: Note: This table presents OLS estimations of cumulative abnormal returns (CAR) against different explanatory variables with country fixed effects. Panel A shows the CAR accumulated for 2 days after the announcement date. Panel B displays the CAR accumulated for 2 days starting 3 days before the announcement date. (Govt+Financial) $* S^{Y i e l d}$ is an indicator variable that is 1 for government related and financial firms and that is interacted with the 2-day change in the yield (in basis points) for each country 2 days after the announcement date multiplied by -1 . Tradable $* S^{E R}$ is an indicator variable for firms in tradable industries following the Mian and Sufi (2014) classification that is interacted with with the 2-day change in the log exchange rate (in percentage) for each country 2 days after the announcement date multiplied by -1 . External FD $* S^{Y i e l d}$ is a proxy of the financial external dependence that is interacted with the yield 2-day change for the announcement date. We compute External FD following Rajan and Zingales (1998) as capital expenditures minus cash flows from operations over capital expenditures, using balance sheet data relative to the year preceding the shock. The detrended returns are excess returns minus their average in the previous year. The 1-factor model contains the domestic stock market index as the only factor. The 3-factor model includes, on top of the local factor, a regional factor (the MSCI EM Index), and a global factor (the MSCI World Index). The 6-factor models adds the small minus big (SMB), high minus low (HML), and momentum (WML) factors. The estimation only includes firms that trade in the domestic market. We discard CAR that are outside the 1 th and 99 th percentile of the distribution for each country. Standard errors are in parenthesis and are clustered at the industry level. *,**,***, denotes significance levels at the 10,5 , and 1 percent level, respectively.

\begin{tabular}{|c|c|c|c|c|}
\hline \multicolumn{5}{|c|}{ Panel A: 2-Day Cumulative Abnormal Returns (Announcement Date) } \\
\hline & rended Returns & 1-Factor Model & 3-Factor Model & 6-Factor Model \\
\hline \multirow[t]{2}{*}{$($ Govt + Financial $) * S^{Y i e l d}$} & $0.018 * * *$ & $0.012^{* *}$ & $0.013^{* *}$ & $0.011^{*}$ \\
\hline & $(0.006)$ & $(0.006)$ & $(0.006)$ & $(0.006)$ \\
\hline \multirow{2}{*}{ Tradable** $S^{E R}$} & $-0.401^{* *}$ & $-0.452^{* * *}$ & $-0.473^{* * *}$ & -0.240 \\
\hline & $(0.155)$ & $(0.163)$ & $(0.162)$ & $(0.192)$ \\
\hline \multirow[t]{2}{*}{ External FD* $S^{Y i e l d}$} & $0.001^{* * *}$ & $0.001^{* * *}$ & $0.001^{* * *}$ & $0.002^{* *}$ \\
\hline & $(0.000)$ & $(0.000)$ & $(0.000)$ & $(0.001)$ \\
\hline Country FE & Yes & Yes & Yes & Yes \\
\hline N. of Countries & 6 & 6 & 6 & 6 \\
\hline Observations & 569 & 572 & 571 & 573 \\
\hline $\mathrm{R}^{2}$ & 0.04 & 0.04 & 0.04 & 0.03 \\
\hline \multicolumn{5}{|c|}{ Panel B: 2-Day Cumulative Abnormal Returns (3 days before Announcement Date) } \\
\hline \multicolumn{2}{|c|}{ Detrended Returns } & 1-Factor Model & 3-Factor Model & 6-Factor Model \\
\hline \multirow[t]{2}{*}{$($ Govt + Financial $) * S^{Y i e l d}$} & 0.001 & -0.002 & -0.002 & 0.003 \\
\hline & $(0.007)$ & $(0.007)$ & $(0.007)$ & $(0.006)$ \\
\hline \multirow[t]{2}{*}{ Tradable** $S^{E R}$} & 0.129 & 0.132 & 0.136 & 0.127 \\
\hline & $(0.180)$ & $(0.172)$ & $(0.170)$ & $(0.169)$ \\
\hline \multirow[t]{2}{*}{ External FD* $S^{Y i e l d}$} & 0.001 & 0.001 & 0.001 & 0.001 \\
\hline & $(0.001)$ & $(0.001)$ & $(0.001)$ & $(0.001)$ \\
\hline Country FE & Yes & Yes & Yes & Yes \\
\hline N. of Countries & 6 & 6 & 6 & 6 \\
\hline Observations & 573 & 573 & 573 & 573 \\
\hline $\mathrm{R}^{2}$ & 0.01 & 0.01 & 0.01 & 0.00 \\
\hline
\end{tabular}


Table A.2: Estimations with Risk Free Rate and Domestic Stock Market

Note: Note: This table presents OLS estimations of cumulative abnormal returns (CAR) against different explanatory variables with country fixed effects. Panel A shows the CAR accumulated for 2 days after the announcement date. Panel B displays the CAR accumulated for 2 days starting 3 days before the announcement date. (Govt+Financial) $* S^{Y i e l d}$ is an indicator variable that is 1 for government related and financial firms and that is interacted with the 2-day change in the yield (in basis points) for each country 2 days after the announcement date multiplied by -1 . Tradable $* S^{E R}$ is an indicator variable for firms in tradable industries following the Mian and Sufi (2014) classification that is interacted with with the 2-day change in the log exchange rate (in percentage) for each country 2 days after the announcement date multiplied by -1 . External FD $* S^{Y i e l d}$ is a proxy of the financial external dependence that is interacted with the yield 2-day change for the announcement date. We compute External FD following Rajan and Zingales (1998) as capital expenditures minus cash flows from operations over capital expenditures, using balance sheet data relative to the year preceding the shock. The detrended returns are excess returns minus their average in the previous year. The 1-factor model contains the domestic stock market index minus the risk-free rate as the only factor. The 3-factor model includes, on top of the local factor, a regional factor (the MSCI EM Index), and a global factor (the MSCI World Index). The 6-factor models adds the small minus big (SMB), high minus low (HML), and momentum (WML) factors. The estimation only includes firms that trade in the domestic market. We discard CAR that are outside the 1th and 99th percentile of the distribution for each country. Standard errors are in parenthesis and are clustered at the industry level. *,**,***, denotes significance levels at the 10,5 , and 1 percent level, respectively.

\begin{tabular}{|c|c|c|c|c|}
\hline \multicolumn{5}{|c|}{ Panel A: 2-Day Cumulative Abnormal Returns (Announcement Date) } \\
\hline & rended Returns & 1-Factor Model & 3-Factor Model & 6-Factor Model \\
\hline \multirow[t]{2}{*}{$($ Govt + Financial $) * S^{Y i e l d}$} & $0.018^{* * *}$ & $0.012^{* *}$ & $0.013^{* *}$ & $0.011^{*}$ \\
\hline & $(0.006)$ & $(0.006)$ & $(0.006)$ & $(0.006)$ \\
\hline \multirow[t]{2}{*}{ Tradable** $S^{E R}$} & $-0.401^{* *}$ & $-0.451^{* * *}$ & $-0.473^{* * *}$ & -0.231 \\
\hline & $(0.153)$ & $(0.163)$ & $(0.162)$ & $(0.194)$ \\
\hline \multirow[t]{2}{*}{ External FD* $S^{Y i e l d}$} & $0.001^{* * *}$ & $0.001^{* * *}$ & $0.001^{* * *}$ & $0.002^{* *}$ \\
\hline & $(0.000)$ & $(0.000)$ & $(0.000)$ & $(0.001)$ \\
\hline Country FE & Yes & Yes & Yes & Yes \\
\hline N. of Countries & 6 & 6 & 6 & 6 \\
\hline Observations & 569 & 572 & 571 & 573 \\
\hline $\mathrm{R}^{2}$ & 0.04 & 0.04 & 0.04 & 0.03 \\
\hline \multicolumn{5}{|c|}{ Panel B: 2-Day Cumulative Abnormal Returns (3 days before Announcement Date) } \\
\hline & Detrended Returns & 1-Factor Model & 3-Factor Model & 6-Factor Model \\
\hline \multirow[t]{2}{*}{$($ Govt + Financial $) * S^{Y i e l d}$} & 0.001 & -0.002 & -0.002 & 0.003 \\
\hline & $(0.007)$ & $(0.007)$ & $(0.007)$ & $(0.006)$ \\
\hline \multirow[t]{2}{*}{ Tradable** $S^{E R}$} & 0.129 & 0.134 & 0.138 & 0.129 \\
\hline & $(0.181)$ & $(0.172)$ & $(0.171)$ & $(0.169)$ \\
\hline \multirow[t]{2}{*}{ External $\mathrm{FD}^{*} S^{Y \text { ield }}$} & 0.001 & 0.001 & 0.001 & \multirow{2}{*}{$\begin{array}{c}0.001 \\
(0.001)\end{array}$} \\
\hline & $(0.001)$ & $(0.001)$ & $(0.001)$ & \\
\hline Country FE & Yes & Yes & Yes & Yes \\
\hline N. of Countries & 6 & 6 & 6 & 6 \\
\hline Observations & 573 & 573 & 573 & 573 \\
\hline $\mathrm{R}^{2}$ & 0.01 & 0.01 & 0.01 & 0.00 \\
\hline
\end{tabular}




\section{B Benchmarks and Selection of Events}

\section{B.1 International Benchmark Indexes for Local Currency Sovereign Bond Mar- kets}

With the rise of financial globalization, global indexes have gained increasing importance in recent years. Such indexes combine and track assets of different classes and countries, and are widely used as benchmarks for international investors. Index providers - such as J.P. Morgan, MSCI Inc., and Citigroup - construct these indexes selecting a set of securities that fall within the scope of each index, defined on the basis of asset class, geographical location, and industry, and satisfy some previously established requirements in terms of market capitalization, liquidity, accessibility to investors, and others.

The return from the index is then calculated as the weighted average of the returns from the securities that are included in it. The weighting procedure can differ across indexes, but the weight assigned to each security typically depends on the relative importance of the asset, in terms of market capitalization, compared to the rest of the constituents. Most of these global indexes are so constructed with a bottom-up approach, and countries can be more or less represented in the index depending on the size of their markets for the specific asset class(es) included.

Two of the main and most widely tracked international indexes for local currency-denominated government debt securities are the World Government Bond Index (WGBI) and J.P. Morgan Government Bond Index Emerging Markets (GBI-EM), which are provided by Citigroup and J.P. Morgan, respectively. Both indexes represent a key benchmark for local currency-denominated sovereign fixed income markets. However, while the former tracks the returns on sovereign bonds denominated in local currency issued by the governments of both developed and emerging countries, the latter solely focuses on emerging countries.

Hence, some emerging countries, as for instance Mexico, appear in both indexes. However, given the heterogenous composition of the two and the different average market capitalization of included securities - the average market capitalization of assets in the WGBI is much larger than 
Table A.3: External Financial Dependence at the Industry Level

Note: This table presents OLS estimations of cumulative abnormal returns (CAR) against different explanatory variables with country fixed effects. Panel A shows the CAR accumulated for 2 days after the announcement date. Panel B displays the CAR accumulated for 2 days starting 3 days before the announcement date. (Govt+Financial) $* S^{Y i e l d}$ is an indicator variable that is 1 for government related and financial firms and that is interacted with the 2-day change in the yield (in basis points) for each country 2 days after the announcement date multiplied by -1 . Tradable $* S^{E R}$ is an indicator variable for firms in tradable industries following the Mian and Sufi (2014) classification that is interacted with with the 2-day change in the log exchange rate (in percentage) for each country 2 days after the announcement date multiplied by -1 . External $\mathrm{FD} * S^{Y \text { ield }}$ is a proxy of the financial external dependence that is interacted with the yield 2-day change for the announcement date. We compute External FD following Rajan and Zingales (1998) as capital expenditures minus cash flows from operations over capital expenditures, using balance sheet data relative to the year preceding the shock. The detrended returns are excess returns minus their average in the previous year. The 1 -factor model contains a regional factor (the MSCI EM Index). The 2-factor model contains includes, on top of the regional factor (the MSCI EM Index), a global factor (the MSCI World Index). The 5-factor models adds the small minus big (SMB), high minus low (HML), and momentum (WML) factors. The estimation only includes firms that trade in the domestic market. We discard CAR that are outside the 1th and 99th percentile of the distribution for each country. Standard errors are in parenthesis and are clustered at the industry level. *, **, ***, denotes significance levels at the 10,5 , and 1 percent level, respectively.

\begin{tabular}{|c|c|c|c|c|}
\hline \multicolumn{5}{|c|}{ Panel A: 2-Day Cumulative Abnormal Returns (Announcement Date) } \\
\hline & rended Returns & 1-Factor Model & 2-Factor Model & 5-Factor Model \\
\hline \multirow[t]{2}{*}{$($ Govt+Financial $) * S^{Y i e l d}$} & $0.017^{* * *}$ & $0.018^{* * *}$ & $0.018^{* * *}$ & $0.014^{* * *}$ \\
\hline & $(0.005)$ & $(0.005)$ & $(0.005)$ & $(0.004)$ \\
\hline \multirow[t]{2}{*}{ Tradable** $S^{E R}$} & $-0.322^{* *}$ & -0.262 & $-0.328^{* *}$ & -0.295 \\
\hline & $(0.157)$ & $(0.170)$ & $(0.162)$ & $(0.178)$ \\
\hline \multirow[t]{2}{*}{$\begin{array}{l}\text { External FD } \\
\text { IND* } S^{Y \text { ield }}\end{array}$} & 0.035 & 0.038 & 0.043 & $0.044^{*}$ \\
\hline & $(0.026)$ & $(0.027)$ & $(0.027)$ & $(0.022)$ \\
\hline Country FE & Yes & Yes & Yes & Yes \\
\hline N. of Countries & 6 & 6 & 6 & 6 \\
\hline Observations & 811 & 811 & 811 & 810 \\
\hline $\mathrm{R}^{2}$ & 0.04 & 0.04 & 0.04 & 0.02 \\
\hline \multicolumn{5}{|c|}{ Panel B: 2-Day Cumulative Abnormal Returns (3 days before Announcement Date) } \\
\hline & Detrended Returns & 1-Factor Model & 2-Factor Model & 5-Factor Model \\
\hline \multirow[t]{2}{*}{$($ Govt + Financial $) * S^{Y i e l d}$} & 0.001 & 0.000 & 0.000 & 0.006 \\
\hline & $(0.005)$ & $(0.005)$ & $(0.005)$ & $(0.005)$ \\
\hline \multirow{2}{*}{ Tradable** $S^{E R}$} & -0.017 & -0.064 & -0.046 & -0.018 \\
\hline & $(0.153)$ & $(0.146)$ & $(0.146)$ & $(0.151)$ \\
\hline \multirow[t]{2}{*}{$\begin{array}{l}\text { External FD } \\
\text { IND* } S^{Y \text { ield }}\end{array}$} & -0.025 & -0.024 & -0.026 & -0.064 \\
\hline & $(0.035)$ & $(0.034)$ & $(0.034)$ & $(0.063)$ \\
\hline Country FE & Yes & Yes & Yes & Yes \\
\hline N. of Countries & 6 & 6 & 6 & 6 \\
\hline Observations & 812 & 812 & 812 & 812 \\
\hline $\mathrm{R}^{2}$ & 0.01 & 0.01 & 0.01 & 0.01 \\
\hline
\end{tabular}


that of assets in the GBI-EM - the relative importance (i.e., the weight) that an emerging country has in the WGBI is typically much lower than the weight it has in the GBI-EM. ${ }^{24}$

In virtue of the growth of cross-border capital flows and financial markets integration, an increasing number of international investors, especially mutual funds, investing in sovereign debt markets track their performances against one of these two indexes. In fact, as of 2016, the assets under management benchmarked against the WGBI were approximately 1.5 trillions US dollars, and those benchmarked against the GBI-EM are approximately 200 billion US dollars. In addition, most of these international mutual funds tend to closely resemble the composition of their benchmark index in order to minimize tracking errors. As a consequence of such passive behavior, changes in the index composition trigger large portfolio rebalancings by international investors which in turn produce large capital flows that can have a sizable impact on asset prices as well. ${ }^{25}$

\section{B.2 Selection of Events}

We construct our events by looking at inclusions/exclusions from the two most important local currency government debt indexes for emerging countries, the Citigroup World Government Bond Index (WGBI) and the J.P. Morgan Government Bond Index Emerging Markets (GBI-EM). Then, we impose to conditions for an event to be included in our sample. First, we need that the announcement of the inclusion/exclusion is not driven by any policy changes. This condition leaves out the upgrade of Argentina in the GBI-EM in 2017, and the downgrade of Nigeria from the GBIEM in 2015. Both announcements were driven by the removal or imposition of capital controls. Second, we need to know the exact date of the announcement of the inclusion/exclusion. For the upgrades of Malaysia and Poland into the WGBI we could not find exact announcement dates, so these events are dropped from our sample.

In principle, one could also look at hard currency (U.S. dollar) sovereign debt indexes. In this

\footnotetext{
${ }^{24}$ For instance, Mexican local currency-denominated debt is a key constituent of the GBI-EM index, where it accounts for $10 \%$ of the size of the index, while its weight in WGBI is less than $1 \%$.

${ }^{25}$ Pandolfi and Williams (2019) provide evidence of the passive behavior of international investors in sovereign bond markets, and show that index rebalancings significantly affects the returns of emerging countries sovereign bonds around the rebalancing date).
} 
segment, the most important index for emerging markets is the Emerging Markets Bond Index (EMBI). In principle, a country could join this index if its GNI per capita is below the Index Income Ceiling for 3 consecutive years. However, for the years before 2019 (when balance sheet data is available), we did not find any country that is entering/leaving the index because of this rule. Most countries that join or fall out of the index do so because they are issuing new bonds or bonds are maturing, but they already fulfill with the GNI per capita condition.

\section{B.3 Details on Country Inclusions}

In this section, we detail the announcement process and commentaries on the inclusion of the different countries by Citigroup and J.P. Morgan.

\section{B.3.1 Colombia}

In March 18th 2014, J.P. Morgan released an official announcement of the inclusion of five Colombian treasury bonds (named TES) into th GBI-EM. These bonds matured in 2016, 2018, 2022, 2024 and 2028 and were denominated in local currency. In the official document J.P. Morgan states that "As a result of improved transparency and accesibility for international investors in the local TES market, Colombia sufficiently meets inclusion requirements for complete GBI-EM Global/Diversification inclusion". Around these days we cannot find any news regarding a policy change or a structural change in the bond market. Several news reports do comment that in January 2013, the government of Colombia cut taxes to foreigners that invested in TES and relaxed to costs to open up local accounts (CITATION).

\section{B.3.2 Czech Republic}

In February 22nd 2017, J.P. Morgan announced the inclusion of Czech Republic to the GBI-EM, with nine local currency government bonds eligible for inclusion. In the announcement note they

explained: "Following the annual J.P. Morgan Index Income Ceiling (IIC) Review, Czech Republic 
is eligible for the J.P. Morgan EM suite of indices. Satisfying the established index country criteria, the country's GNI per capita level was below the IIC threshold for three consecutive years. Based on one year lag information published levels from the World Bank, the latest IIC figure stands at $\$ 19,065 "$.

\section{B.3.3 Mexico}

In March 31st 2010, Citigroup announced that Mexico was eligible for WGBI inclusion. In the note, they stated: "If Mexico continues to meet all WGBI criteria for three consecutive months starting with the April 2010 index profile, it will become the first Latin American and the 24th government bond market to enter the WGBI. Entry would be effective October 2010". These are the size, ratings and barriers to foreigners requirements to be included in the index by Citigroup. Several news articles highlighted that Mexico already fulfilled the size and ratings requirements and that during the past year the government of Mexico improved the liquidity of the government bond market by issuing 30 year bonds, selling syndicated debt to foreigners and creating a primary dealers program.

\section{B.3.4 Nigeria}

In August 17th 2012, J.P. Morgan announced the inclusion of Nigerian bonds into the GBI-EM. These bonds (named FGN) were long-term and denominated in local currency and matured in 2014, 2019 and 2022. In a research commentary J.P. Morgan higlighted that "while Nigeria, as a country, has been eligible for inclusion for some time, only recently has the debt market become sufficiently liquid to proceed with inclusion". In the same research note they detailed that "in June 2011, the Central Bank of Nigeria (CBN) announced the removal of the one-year lock-in period for foreign investment in government securities. This paved the way for increased activity by international investors in the local debt market and generally supported higher levels of market liquidity, allowing for index entry". 


\section{B.3.5 Romania}

In January 16th 2013, J.P. Morgan announced the inclusion of Romanian government bonds into the GBI-EM. These bonds (named RON) were denominated in local currency and matured in 2015, 2016 and 2017. In a commentary note J.P. Morgan highlighted: "The current IIC is $\$ 17,726$, with Romania's GNI per capita currently at $\$ 7,910$. As such, Romania has been eligible for inclusion in the GBI-EM series for several years, as its GNI per capita is below the IIC. However, despite country eligibility, the bond level accessibility and secondary market liquidity has historically been a barrier. Over the past 18-months, however, liquidity has increased with sustained primary market activity and secondary market accessibility, making RON debt eligible for entry into the GBI-EM series".

\section{B.3.6 South Africa}

In April 16th 2012, Citigroup announced that South Africa was eligible for inclusion in the WGBI. In the note they stated: "The South African Government Bond Index satisfies all three World Government Bond Index (WGBI) requirements - size, credit quality and the lack of barriers to entry - with the April 2012 profile; therefore, it is eligible for inclusion in the WGBI. If South Africa continues to meet all WGBI criteria with the May and June 2012 profiles, it will become the first African government bond market to be included in the WGBI, bringing the number of sovereign markets to 23, effective October 2012". South Africa already satisfied the ratings and size

requirement with certainty. It is possible that some developments in the accesibility of foreigners to the government bond market changed through 2011, but news articles around the announcement do not highlight this. 